\title{
Nano-Sized Iron Sulfide: Structure, Synthesis, Properties, and Biomedical Applications
}

\author{
Ye Yuan ${ }^{1,2,3}$, Liping Wang ${ }^{1,2}$ and Lizeng Gao ${ }^{3,4 *}$ \\ ${ }^{1}$ Key Laboratory for Molecular Enzymology and Engineering, The Ministry of Education, Jilin University, Changchun, China, \\ ${ }^{2}$ School of Life Sciences, Jilin University, Changchun, China, ${ }^{3}$ CAS Engineering Laboratory for Nanozyme, Institute of \\ Biophysics, Chinese Academy of Sciences, Beijing, China, ${ }^{4}$ Nanozyme Medical Center, School of Basic Medical Sciences, \\ Zhengzhou University, Zhengzhou, China
}

Nano-sized iron sulfides have attracted intense research interest due to the variety of their types, structures, and physicochemical properties. In particular, nano-sized iron sulfides exhibit enzyme-like activity by mimicking natural enzymes that depend on an iron-sulfur cluster as cofactor, extending their potential for applications in biomedicine. The present review principally summarizes the synthesis, properties and applications in biomedical fields, demonstrating that nano-sized iron sulfides have considerable potential for improving human health and quality of life.

Keywords: nano-sized iron sulfide, structure, synthesis, enzyme-like activities, biomedical applications

\section{OPEN ACCESS}

Edited by:

Youhui Lin,

Xiamen University, China

Reviewed by:

Xian Chen,

Shenzhen University, China

Amitava Adhikary,

Oakland University, United States

*Correspondence:

Lizeng Gao

gaolizeng@ibp.ac.cn

Specialty section:

This article was submitted to

Nanoscience,

a section of the journal

Frontiers in Chemistry

Received: 19 May 2020

Accepted: 04 August 2020

Published: 10 September 2020

Citation:

Yuan Y, Wang L and Gao L (2020) Nano-Sized Iron Sulfide: Structure,

Synthesis, Properties, and Biomedical Applications. Front. Chem. 8:818. doi: 10.3389/fchem.2020.00818

\section{INTRODUCTION}

With the development of nanotechnology (Li et al., 2019), nanomaterials have become a major resource for the development of novel therapeutic medicines and technologies designed to improve human health and the quality of life (Zhang and Webster, 2009; Esmaeili et al., 2020; Wang et al., 2020). In particular, due to their multiple functionality and excellent biocompatibility, ironbased nanomaterials are frequently used in the biomedical field, such as bioseparation, biosensors, magnetic resonance imaging (MRI), tumor hyperthermia, and drug delivery (Chen and Gu, 2017). In addition, recent studies have revealed that these nanomaterials have intrinsic enzyme-like properties (Gao et al., 2007; Xie et al., 2012; Xu et al., 2018), an important form of nanozyme representing a new generation of artificial enzyme (Wei and Wang, 2013; Dong et al., 2019; Liang and Yan, 2019). Currently, the majority of iron-based nanomaterials are iron oxide which possess excellent supraparamagnetic properties, with catalytic activity mimicking that of oxidoreductases, including peroxidase, catalase, superoxide dismutase, and oxidase (Gao et al., 2007; Liang and Yan, 2019). However, iron sulfide nanomaterials have not been comprehensively studied or used in the biomedical fields. Since O and S are congeneric elements, iron sulfide demonstrates similar physiochemical properties as iron oxide (Fu et al., 2019). In addition, the phases of iron sulfide in nature include mackinawite $(\mathrm{FeS})$, pyrrhotite $\left(\mathrm{Fe}_{1-\mathrm{x}} \mathrm{S}\right)$, pyrite $\left(\mathrm{FeS}_{2}\right)$, and greigite $\left(\mathrm{Fe}_{3} \mathrm{~S}_{4}\right)$, etc., which exhibit more variability than iron oxide containing only $\mathrm{Fe}_{2} \mathrm{O}_{3}$ and $\mathrm{Fe}_{3} \mathrm{O}_{4}$. The band gap in iron sulfide is smaller than that of iron oxide, leading to the former having more appropriate electron transfer and conductivity (Wadia et al., 2009; Jin et al., 2017; Zhang et al., 2018). Importantly, iron-sulfur clusters are important cofactors in many enzymes which serve as active centers for electron transfer in catalytic processes and respiratory chain reactions (Qi and Cowan, 2011). Therefore, it is anticipated that iron sulfide nanomaterials will display multiple functionalities and they have great potential in biomedical applications. Herein, we will summarize 
the types, synthesis and properties of iron sulfide nanomaterials and emphasize their applications in biomedical and medical fields. This will provide a comprehensive understanding of iron sulfide nanomaterials and illustrate their considerable potential as novel multifunctional biomaterials in biomedical applications.

\section{TYPE AND STRUCTURE OF IRON SULFIDE}

Solid phases of iron sulfides principally comprise FeS (mackinawite), $\mathrm{Fe}_{1-\mathrm{x}} \mathrm{S}$ (pyrrhotite), $\mathrm{FeS}_{2 \mathrm{p}}$ (pyrite), $\mathrm{FeS}_{2 \mathrm{~m}}$ (marcasite), $\mathrm{Fe}_{3} \mathrm{~S}_{4}$ (greigite), and $\mathrm{Fe}_{9} \mathrm{~S}_{11}$ (smythite). The content of iron within a biomaterial therefore influences its phase, shape, and physical and chemical properties. FeS naturally has a tetragonal structure, with each iron atom coordinated to four sulfurs. For $\mathrm{Fe}_{1-x} \mathrm{~S}$, a monoclinic hexagonal is present. $\mathrm{FeS}_{2 \mathrm{p}}$ forms stable iron (II) disulfides with cubic structures. $\mathrm{FeS}_{2 \mathrm{~m}}$ differs from $\mathrm{FeS}_{2 \mathrm{p}}$ as an orthorhombic metastable iron (II) disulfide, whilst $\mathrm{Fe}_{3} \mathrm{~S}_{4}$ is a cubic metastable $\mathrm{Fe}$ (II) $\mathrm{Fe}$ (III) sulfide. Hexagonal $\mathrm{Fe}_{9} \mathrm{~S}_{11}$ is related to the $\mathrm{Fe}_{1-\mathrm{x}} \mathrm{S}$ phase (Rickard and Luther, 2007).

Reported crystal structures of iron sulfide are displayed in Figure 1 (Fleet, 1971; Argueta-Figueroa et al., 2017). FeS possesses a tetragonal layered structure in which the iron atoms are linked through tetrahedral coordination to four equidistant sulfur atoms. A single iron atom is coordinated to four equidistant sulfur atoms. The distance of Fe-Fe is 2.5967 $\AA$ A. In addition, Fe-Fe bonding is substantial in FeS. To assess the effects of van der Waals forces resulting from the $S$ atoms, sheets including $\mathrm{Fe}$ are stacked along the $\mathrm{C}$-axis. The spacing of these layers is $5 \AA$. The structure of $\mathrm{Fe}_{2} \mathrm{~S}_{2}$ is closed to $\mathrm{FeS}$. The structure of $\mathrm{FeS}_{2}$ is similar to that of $\mathrm{NaCl}$ in which $\mathrm{S}^{2-}$ is located at the center of a cube. The cubic structure has a low symmetry. In addition, $\mathrm{FeS}_{2}$ exhibits chirality through absorbed organic molecules. $\mathrm{Fe}_{3} \mathrm{~S}_{4}$ has an inverse spinel structure in which $8 \mathrm{Fe}$ atoms are located at the tetrahedral A-sites and $16 \mathrm{Fe}$ atoms are located at the B-sites of the octahedron. The unit cell of $\mathrm{Fe}_{3} \mathrm{~S}_{4}$ is $9.876 \AA$. In addition, the cubic structure of $\mathrm{Fe}_{3} \mathrm{~S}_{4}$ forms a closely packed array of $\mathrm{S}$ molecules linked by smaller $\mathrm{Fe}$ units (Figure 1D). It has been established that the $\mathrm{Fe}_{7} \mathrm{~S}_{8}$ structure is a hexagonal supercell (Fleet, 1971). The viable distribution of vacancy sites ideal for the base structure of NiAs was observed to describe the structure of $\mathrm{Fe}_{9} \mathrm{~S}_{10}$ (Elliot, 2010).

\section{SYNTHESIS OF NANO-SIZED IRON SULFIDES}

Nano-sized iron sulfide encompasses a range of iron and sulfur compounds. Firstly, the range of chemical and biological methods for their production are discussed. In addition, the most reported synthesized methods for creating different phases of iron sulfide are presented in Table 1.

\section{Hydrothermal Synthesis}

Thermal decomposition is the most commonly-used hydrothermal reaction for iron sulfide production. The typical solvothermal synthesis method of $\mathrm{nFeS}$ firstly involves the dissolution of $\mathrm{FeCl}_{3} \cdot 6 \mathrm{H}_{2} \mathrm{O}$ in $40 \mathrm{~mL}$ of ethylene glycol. $\mathrm{NaOAc}$ and organosulfur compounds (allyl methyl sulfide, diallyl sulfide, diallyl trisulfide, diallyl disulfide, cysteine, cystine, glutathione (GSH), or methionine) are then added under continuous and vigorous stirring. The system was then sonicated for $10 \mathrm{~min}$ and transferred to a Teflon-lined stainless steel autoclave. The mixture was reacted at $200^{\circ} \mathrm{C}$ for $12 \mathrm{~h}$ and precipitates washed three times with ethanol and water. Finally, the products were dried at $60^{\circ} \mathrm{C}$ for $3 \mathrm{~h}$ ( $\mathrm{Xu}$ et al., 2018). For $\mathrm{FeS}_{2}$, the single source molecular precursor $\mathrm{Fe}^{3+}$ diethyl dithiophosphate forms an aqueous solution through the reaction of $\mathrm{FeCl}_{3}$ and $\left(\mathrm{C}_{2} \mathrm{H}_{5} \mathrm{O}\right)_{2} \mathrm{P}(\mathrm{S}) \mathrm{SNH}_{4}$, with hexadecyltrimethylammonium bromide $(\mathrm{CTAB})$ added as a surfactant and reacted with a single precursor $\left[\left(\mathrm{C}_{2} \mathrm{H}_{5} \mathrm{O}\right)_{2} \mathrm{P}(\mathrm{S}) \mathrm{S}\right]_{3} \mathrm{Fe}$ (Wadia et al., 2009). For FeS, $\mathrm{FeCl}_{3} \cdot 6 \mathrm{H}_{2} \mathrm{O}$ was dissolved in ultrapure water with ethanolamine and thiourea added to the solution. After stirring for $25 \mathrm{~min}$, the mixture was added to a Teflon lined autoclave and reacted at $180^{\circ} \mathrm{C}$ for $12 \mathrm{~h}$. The synthesis of $\mathrm{Fe}_{3} \mathrm{~S}_{4}$ differs from that of FeS. $\mathrm{FeCl}_{3} \cdot 6 \mathrm{H}_{2} \mathrm{O}$, ethylene glycol, thiourea and $\mathrm{H}_{2} \mathrm{O}_{2}$ were mixed and reacted at $180^{\circ} \mathrm{C}$ for $18 \mathrm{~h}$ in the presence of the capping agent polyvinyl pyrrolidone (PVP) to prevent excessive growth and aggregation of the nanoparticles (NPs) (Moore et al., 2019). $\mathrm{Fe}_{1-\mathrm{X}} \mathrm{S}$ single crystals were then synthesized through a hydrothermal method by the addition of $\mathrm{K}_{0.8} \mathrm{Fe}_{1.6} \mathrm{~S}_{2}$ crystals, Fe powder, $\mathrm{NaOH}$, and thiourea in deionized water, which was reacted at $120^{\circ} \mathrm{C}$ for $3-4$ days (Guo et al., 2017). Ionic liquids that form extended hydrogen bond systems were then used to form higher structures in the base of the hydrothermal process, as reported by Zheng and colleagues when changing the structure of $\mathrm{Fe}_{3} \mathrm{~S}_{4}$ (Ma et al., 2010). Generally speaking, the product obtained by the hydrothermal method has better dispersibility and controllability, but iron oxide impurities can also appear during the synthesis of iron sulfide. Meanwhile, multiphase iron sulfide appears to occur easily, as assessed by X-ray diffraction (XRD) patterns for hydrothermally-synthesized samples.

\section{Microwave Production}

The principal advantages of microwave-assisted methods, compared with conventional heating include its reduced reaction time, smaller particle size distribution, and higher purity. Ethylene glycol is a solvent suitable for microwave-assisted methods owing to its relatively high dipole moment. For $\mathrm{FeS}_{2}$ microspherolites, $\mathrm{FeSO}_{4} \cdot 7 \mathrm{H}_{2} \mathrm{O}$, PVP-K30 and $\mathrm{S}$ powder in ethylene glycol can be reacted by microwave in an $\mathrm{N}_{2}$ atmosphere (Li M. et al., 2011). Although this emerging technique may be more desirable it should be noted that the aggregation phenomenon does not appear to be improved.

\section{Co-precipitation}

Chemical co-precipitation does not introduce impurities. The operation is performed under mild conditions and is typically synthesized using $\mathrm{Fe}_{3} \mathrm{~S}_{4}$ methods, in which iron (II) sulfate heptahydrate and sodium sulfide are dissolved in ultrapure deionized water. The solution was then added dropwise to acetic acid to adjust the $\mathrm{pH}$ to 3.0, followed by stirring for several minutes. The reaction was prepared under an $\mathrm{N}_{2}$ atmosphere (Chang et al., 2011). In addition, green synthesis was achieved 
A

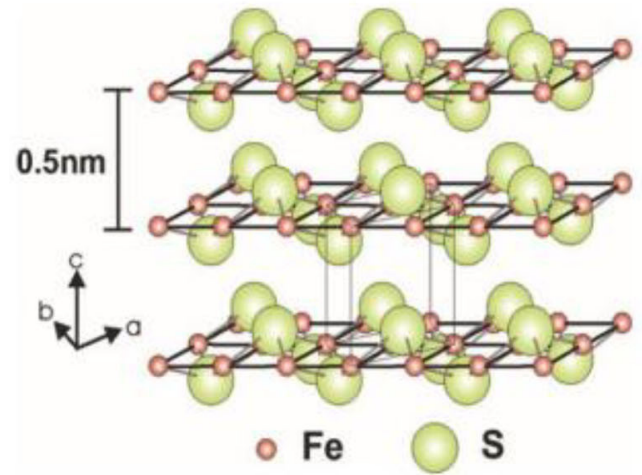

C

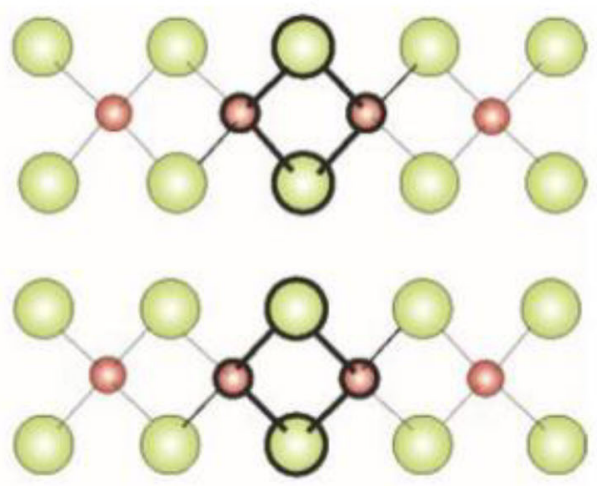

B

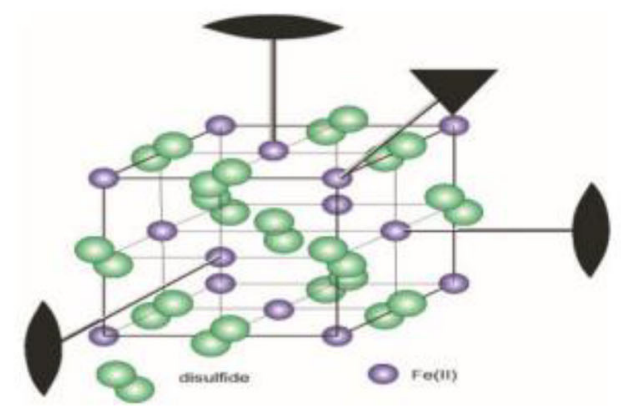

D

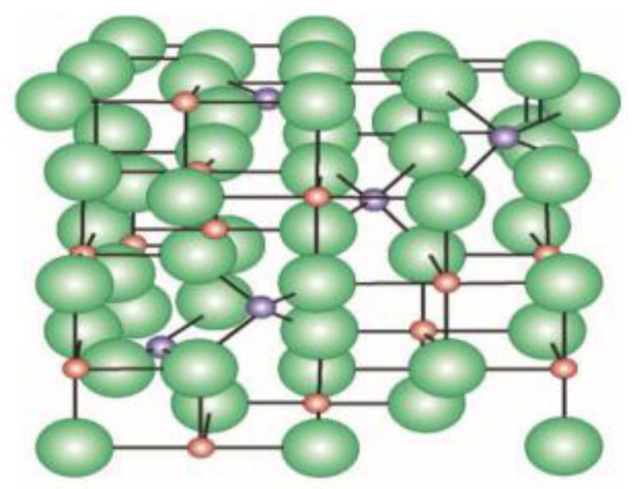

FIGURE 1 | Crystal structure of iron sulfide. (A) FeS. (B) $\mathrm{FeS}_{2}$. (C) $\mathrm{Fe}_{2} \mathrm{~S}_{2}$. (D) $\mathrm{Fe}_{3} \mathrm{~S}_{4}$. Reproduced with permission from Rickard and Luther (2007). Copyright 2007, American Chemical Society.

in a continuous stirred-tank reactor (Simeonidis et al., 2016). As previously reported, the conditions of synthesis required by coprecipitation are harsher than those of other methods, and the products obtained may show poor homogeneity.

\section{High Temperature Chemical Synthesis}

Chemical synthesis methods using high temperatures have been reported for $\mathrm{FeS}_{2}$. Briefly, iron (II) acetylacetonate $\left(\mathrm{Fe}(\mathrm{acac})_{2}\right)$, trioctylphosphine oxide (TOPO) and oleyamine (OLA) were mixed and degassed at $110^{\circ} \mathrm{C}$ for $1 \mathrm{~h}$ under a vacuum. The mixture was then rapidly heated to $220^{\circ} \mathrm{C}$ for $1 \mathrm{~h}$ under vigorous magnetic stirring in the presence of nitrogen. Sulfur was then quickly injected into the solution, which was heated to $220^{\circ} \mathrm{C}$ for $1 \mathrm{~h}$. Once the solution cooled, ethanol was added to the precipitate to develop the $\mathrm{FeS}_{2}$ nanoplates (Bi et al., 2011). Synthesis methods for $\mathrm{Fe}_{1-\mathrm{x}} \mathrm{S}$ and $\mathrm{Fe}_{3} \mathrm{~S}_{4}$ have also been reported. The rapid injection method has been used to reduce the size of $\mathrm{Fe}_{3} \mathrm{~S}_{4}$ (Beal et al., 2012). This method of synthesis is highly sensitive to the experimental conditions.

\section{Sonochemical Synthesis}

As a convenient and stable synthetic method, Bala and colleagues described specific FeS' sonochemical synthesis. Firstly, sodium sulfide was dissolved in double distilled water. $\mathrm{FeSO}_{4} \cdot 7 \mathrm{H}_{2} \mathrm{O}$ was then independently dissolved in a solution of double distilled water and polyethylene glycol (1:1). The sodium sulfide solution contained a drop of Triton-X surfactant which was added dropwise to the above solution while being continuously sonicated for $30 \mathrm{~min}$. PVP was then added and the system was mixed via ultrasound for a further $30 \mathrm{~min}$ (Ahuja et al., 2019).

\section{Other Chemical Methods}

Some unusual synthetic chemical methods have been reported. The low temperature synthesis of $\mathrm{FeS}_{2}$ nanoparticles was described in 2014 (Srivastava et al., 2014a). Briefly, $\mathrm{FeCl}_{3}$ and sodium polysulfide $\left(\mathrm{Na}_{2} \mathrm{~S}_{\mathrm{x}}\right)$ were mixed in $\mathrm{pH} 5.6$ acetate buffer in an anaerobic environment. The black solution then was reacted in a $90-100^{\circ} \mathrm{C}$ oil bath for $4 \mathrm{~h}$ to produce a grayish $\mathrm{FeS}_{2}$ product. Flux methods were then used to synthesize 1D $\mathrm{Fe}_{7} \mathrm{~S}_{8}$. The reaction was conducted within a furnace at 750$850^{\circ} \mathrm{C}$ (Kong et al., 2005). FeS can also be created in a biological system (Mei and Ma, 2013).

\section{Biomineralization}

The bio-synthesis of iron sulfide using microorganisms is superior for biomedical applications (Li X. et al., 2011). When microorganisms interact with target ions, they are transported into microbial cells to form NPs in the presence of specific enzymes. In addition to the advantages of green synthesis, biological methods improve the biocompatibility of iron sulfide. 
TABLE 1 | Appearances, sizes and lattice spaces of iron sulfide.

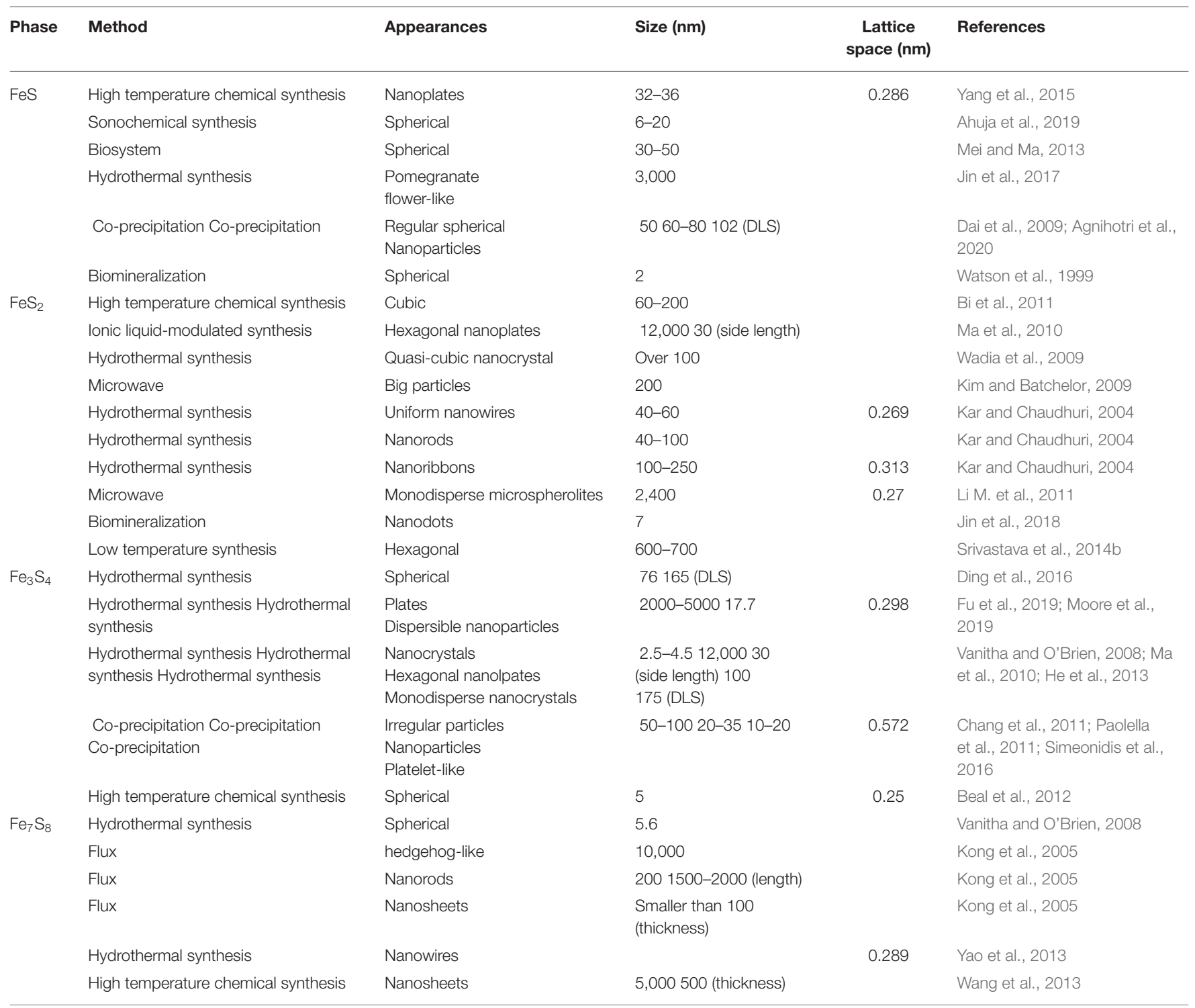

The particles generated have higher catalytic reactivity and a greater surface area. Previous studies have reported that $\mathrm{FeS}_{2}$, $\mathrm{Fe}_{3} \mathrm{~S}_{4}$, and FeS NPs can be produced by microorganisms. For the biomineralization of $\mathrm{Fe}_{3} \mathrm{~S}_{4}$ and $\mathrm{FeS}_{2}$, a magnetotactic bacterium has been described (Mann et al., 1990). In 1995, FeS materials were produced by sulfate-reducing bacteria grown on iron containing substrates (Watson et al., 1995). Bazylinski and colleagues also reported the formation of $\mathrm{Fe}_{3} \mathrm{~S}_{4}$ using noncultured magnetotactic bacteria (Lefèvre et al., 2010). Sulfatereducing bacteria were able to produce $\mathrm{Fe}_{1-\mathrm{x}} \mathrm{S}$ as reported by Charnock and colleagues (Watson et al., 2000). NPs were subsequently formed at the surface by the microorganisms and as such, the porous structure of the iron sulfide NPs failed to prevent normal metabolism. These studies verified the utility of this method for efficient NP production. Chemical biomineralization methods have also been used to synthesize $\mathrm{FeS}_{2}$ and $\mathrm{FeS}$ Quantum dots (QDs) (Jin et al., 2018; Yang et al., 2020).

\section{Iron Sulfide Modifications}

Bare nanocrystal cores have an unstable structure that is prone to photochemical degradation. However, those that are unmodified display higher toxicity. As such, biocompatible moieties are essential as they serve as caps for nanomaterials, including polyethylene glycol (PEG), silica, lactose, citrate, and dextran (Simeonidis et al., 2016; Mofokeng et al., 2017). Previous studies have reported the synthesis, characterization, cytotoxicity and biodistribution of FeS/PEG nanoplates in vivo (Yang et al., 2015). An adsorption-reduction method was used to load silver onto the surface of 3-aminopropyltriethoxysilanemodified 3-aminopropyl triethoxysilane (APTES)-modified $\mathrm{Fe}_{3} \mathrm{~S}_{4}$ particles, achieving the preparation of magnetic composite nanoparticles of $\mathrm{Fe}_{3} \mathrm{~S}_{4} / \mathrm{Ag}$ ( $\mathrm{He}$ et al., 2013). However, modifications also led to adverse effects. For example, the modification of CTAB inhibited the growth of nano $\mathrm{Fe}_{3} \mathrm{~S}_{4}$ (Simeonidis et al., 2016). 

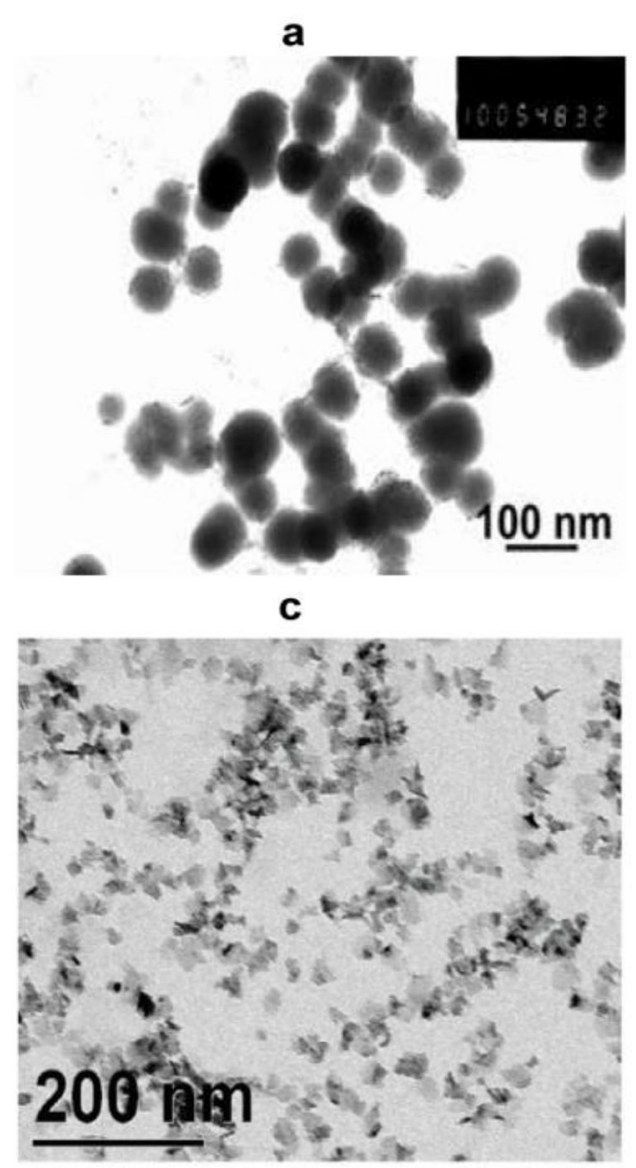

b

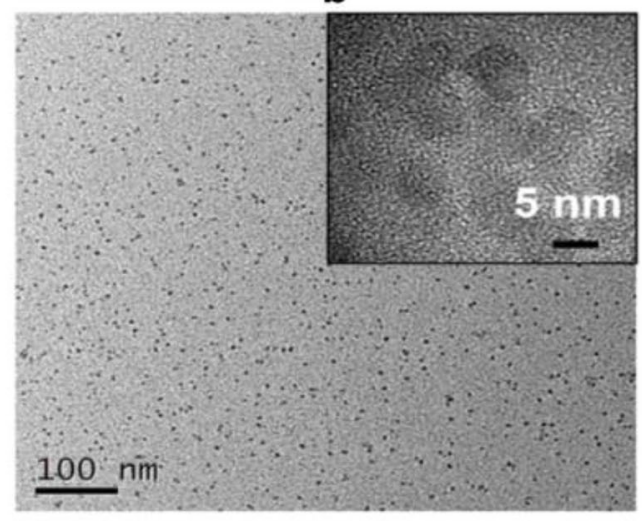

d

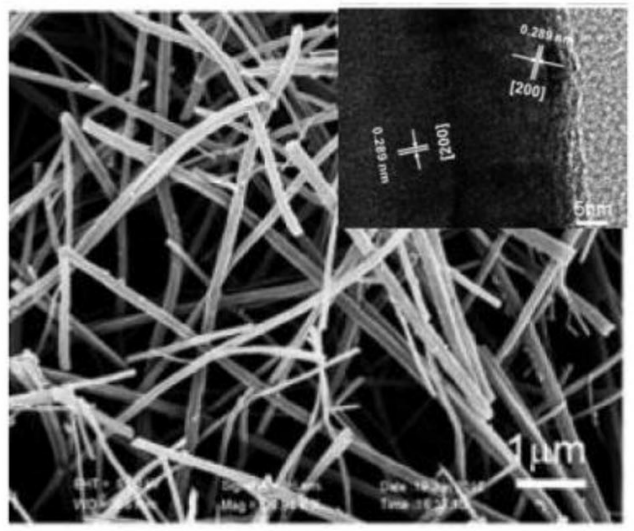

FIGURE 2 | Representative images of nano-sized iron sulfide. (A) TEM image of the spherical FeS. Reproduced with permission from Dai et al. (2009). Copyright 2009, Wiley-VCH Verlag GmbH \& Co. KGaA, Weinheim. (B) TEM and HRTEM of FeS 2 nanodots. Reproduced with permission from Jin et al. (2018). Copyright 2017, American Chemical Society. (C) TEM images of platelet-like $\mathrm{Fe}_{3} \mathrm{~S}_{4}$. Reproduced with permission from Paolella et al. (2011). Copyright 2011, American Chemical Society. (D) SEM and HRTEM of $\mathrm{Fe}_{7} \mathrm{~S}_{8}$ nanowires. Reproduced with permission from Yao et al. (2013). Copyright 2013, Wiley-VCH Verlag GmbH \& Co. KGaA, Weinheim.

\section{Characterization of Iron Sulfide}

Detailed characterization is required to confirm the synthesis of iron sulfide. Scanning electron microscopy (SEM) and transmission electron microscopy (TEM) can be used to image surface morphology. These represent the most direct and commonly-used methods to assess the microstructure, size, and dispersion of the materials. Differences in the synthetic methods have presented variations in TEM/SEM imaging, including within the same phase. For FeS, nanoplates, spherical nanoparticles, and pomegranate flower-like shapes have been reported. $\mathrm{FeS}_{2}$ exists as large particles, cubic nanocrystals, monodisperse microspherolites, spherical and hexagonal nanoribbons, and nanorods. Typical images of iron sulfide are shown in Figure 2. Table 1 reports the most common morphology and size of $\mathrm{FeS}, \mathrm{FeS}_{2}, \mathrm{Fe}_{3} \mathrm{~S}_{4}$, and $\mathrm{Fe}_{7} \mathrm{~S}_{8}$. Lattice spaces are measured to judge the crystallinity of the materials. The reported lattice spaces of the iron sulfides are summarized in Table 1. The composition, content, and structure of a substance can be analyzed, measured, and inferred using Ultraviolet-visible
(UV-Vis) spectrometry and the absorption of UV and visible light. According to previous studies, the UV absorption peaks of FeS are $285 \mathrm{~nm}$ and $500 \mathrm{~nm}$ (Table 2). Information on the composition of the materials and the structure and/or morphology of the atoms or molecules inside the materials can be obtained by XRD analysis. XRD is the most direct indicator of whether a crystal is pure and so represents a convenient system to analyze synthesized materials. JCPDS cards are used to contrast and analyze unknown crystals. JCPDS cards of FeS (JCPDS card No. 15-0037 and 75-0602), FeS 2 (JCPDS card No. 03-065-1211, 89-3057, 65-3321, and 42-130), $\mathrm{Fe}_{3} \mathrm{~S}_{4}$ (JCPDS card No. 16-0713, 89-1998, and 16-0073) and $\mathrm{Fe}_{7} \mathrm{~S}_{8}$ (JCPDS card No. 25-0411 and 76-2308) are listed in Table 2. For iron sulfide nanomaterials, the X-ray photoelectron spectroscopy (XPS) of $\mathrm{Fe}$ and $\mathrm{S}$ are essential. FeS materials are presented in Table 2 (Fe $2 \mathrm{p}: 2 \mathrm{p}_{3 / 2}(711.4 \mathrm{eV}), 2 \mathrm{p}_{1 / 2}(724.9 \mathrm{eV}), \mathrm{S} 2 \mathrm{p}: 2 \mathrm{p}_{3 / 2}(161.1 \mathrm{eV})$ $\left.2 \mathrm{p}_{1 / 2}(166.0 \mathrm{eV})\right), \mathrm{FeS}_{2}\left(\mathrm{Fe} 2 \mathrm{p}: 2 \mathrm{p}_{3 / 2}(707.0 \mathrm{eV}), 2 \mathrm{p}_{1 / 2}(720.0 \mathrm{eV})\right.$, S 2 p $\left.2 p_{3 / 2}(162.3 \mathrm{eV}), 2 \mathrm{p}_{1 / 2}(163.5 \mathrm{eV})\right), \mathrm{Fe}_{3} \mathrm{~S}_{4}\left(\mathrm{Fe} 2 \mathrm{p}: 2 \mathrm{p}_{3 / 2}\right.$ $\left.(711.0 \mathrm{eV}), \mathrm{S} 2 \mathrm{p}: 2 \mathrm{p}_{3 / 2}(161.0 \mathrm{eV}), 2 \mathrm{p}_{1 / 2}(162.5 \mathrm{eV})\right), \mathrm{Fe}_{7} \mathrm{~S}_{8}(\mathrm{Fe}$ 
TABLE 2 | UV-VIS, XPS and XRD of iron sulfide.

\begin{tabular}{|c|c|c|c|c|}
\hline Phase & UV-Vis peak (nm) & XPS & XRD & References \\
\hline FeS & $\begin{array}{l}500285 \text { A broad } \\
\text { absorption in }(400-700 \mathrm{~nm})\end{array}$ & $\begin{array}{l}\text { Fe } 2 p 2 p_{3 / 2}\left(711.4 \text { eV) } 2 p_{1 / 2}(724.9 e V)\right. \\
\text { S 2p 2p } p_{3 / 2}(161.1 e V) 2 p_{1 / 2}(166.0 \mathrm{eV})\end{array}$ & $\begin{array}{l}\text { JCPDS card No.15-0037 } \\
\text { JCPDS card No.75-0602 }\end{array}$ & $\begin{array}{l}\text { Guo et al., 2016; Jin et al., 2017; Ahuja et al., } \\
\text { 2019; Agnihotri et al., } 2020\end{array}$ \\
\hline $\mathrm{FeS}_{2}$ & & $\begin{array}{l}\text { Fe } 2 p 2 p_{3 / 2}(707.0 \mathrm{eV}) 2 \mathrm{p}_{1 / 2}(720.0 \mathrm{eV}) \\
\mathrm{S} 2 \mathrm{p} 2 \mathrm{p}_{3 / 2}(162.3 \mathrm{eV}) 2 \mathrm{p}_{1 / 2}(163.5 \mathrm{eV})\end{array}$ & $\begin{array}{l}\text { JCPDS card No.03-065-1211 } \\
\text { JCPDS card No.89-3057 } \\
\text { JCPDS card No.65-3321 } \\
\text { JCPDS card No.42-1340 }\end{array}$ & $\begin{array}{l}\text { Kar and Chaudhuri, 2004; Wadia et al., 2009; } \\
\text { Li M. et al., 2011; Gan et al., } 2016\end{array}$ \\
\hline $\mathrm{Fe}_{3} \mathrm{~S}_{4}$ & & $\begin{array}{l}\text { Fe } 2 p 2 p_{3 / 2}(711.0 \mathrm{eV}) \\
\mathrm{S} 2 \mathrm{p} 2 \mathrm{p}_{3 / 2}(161.0 \mathrm{eV}) 2 \mathrm{p}_{1 / 2}(162.5 \mathrm{eV})\end{array}$ & $\begin{array}{l}\text { JCPDS card No.16-0713 } \\
\text { JCPDS card No.89-1998 } \\
\text { JCPDS card No.16-0073 }\end{array}$ & $\begin{array}{l}\text { Ma et al., 2010; Chang et al., 2011; Paolella } \\
\text { et al., 2011; Beal et al., 2012; Feng et al., } \\
\text { 2013; He et al., 2013; Ding et al., 2016; Moore } \\
\text { et al., } 2019\end{array}$ \\
\hline $\mathrm{Fe}_{7} \mathrm{~S}_{8}$ & & $\begin{array}{l}\text { Fe 2p 2p3/2 (709.9 eV) }(711.6 \mathrm{eV}) \\
\mathrm{S} 2 \mathrm{p} 2 \mathrm{p}_{3 / 2}(163.5 \mathrm{eV}) 2 \mathrm{p}_{1 / 2}(164.7 \mathrm{eV})\end{array}$ & $\begin{array}{l}\text { JCPDS card No. 25-0411 } \\
\text { JCPDS card No.76-2308 } \\
\text { JCPDS card No.71-0647 }\end{array}$ & $\begin{array}{l}\text { Kong et al., 2005; Vanitha and O'Brien, 2008; } \\
\text { Wang et al., 2013; Yao et al., 2013; Jin et al., } \\
2019\end{array}$ \\
\hline
\end{tabular}

2p: 2p $3 / 2(709.9 \mathrm{eV}),(711.6 \mathrm{eV})$, S $2 \mathrm{p}: 2 \mathrm{p}_{3 / 2}(163.5 \mathrm{eV}), 2 \mathrm{p}_{1 / 2}$ $(164.7 \mathrm{eV})$ ). Fourier transform infrared (FTIR) spectroscopy can be used to detect functional groups in a complex mixture and so is therefore essential to the characterization of modified iron sulfide. Previous studies have provided FTIR spectra, showing successful modifications by APTES on the surface of the $\mathrm{Fe}_{3} \mathrm{~S}_{4}$ nanoparticles (He et al., 2013). $\mathrm{Fe}_{7} \mathrm{~S}_{8} / \mathrm{N}-\mathrm{C}$ nanohybrids were prepared for FeMOF and FeMOF-S and analyzed by FTIR (Jin et al., 2019). In addition, energy dispersive spectroscopy (EDS) (Paolella et al., 2011; Ding et al., 2016; Guo et al., 2016), dynamic light scattering (DLS) (He et al., 2013; Ding et al., 2016), Raman spectroscopy (Gan et al., 2016; Guo et al., 2016), selected area electron diffraction (SAED) (Kar and Chaudhuri, 2004), X-ray absorption fine structure (XAFS) (Feng et al., 2013), differential scanning calorimetry (DSC) and thermogravimetric analysis (TGA) (Jin et al., 2019), nitrogen adsorption-desorption isotherms and pore size distribution (Guo et al., 2016) analysis of iron sulfide have been reported as characterization systems.

\section{CHARACTERISTICS OF NANO-SIZED IRON SULFIDES}

In addition to both the physical and chemical properties, characteristics include the structure, solubility, stability, reactivity, magnetic properties, and photothermal properties of the products.

\section{Solubility}

The major forms of nano-sized iron sulfides are solid precipitates which have poor solubility in water. However, Rickard et al. revealed that sedimental $\mathrm{FeS}$ can dissolve at $\mathrm{c}\left(\mathrm{S}^{2-}\right) \leq 10^{-5.7}$ $\mathrm{M}$ to form $\mathrm{Fe}^{2+}$. The solubility can be increased in an alkaline as opposed to neutral environment (Rickard, 2006). FeS does not dissolve in $\mathrm{HCl}$, meaning it cannot be removed with $\mathrm{HCl}$ (Rickard and Luther, 2007). According to previous studies, the $\mathrm{K}_{\mathrm{sp}}$ of $\mathrm{FeS}_{2}$ was $10^{-16.4}$ at $25^{\circ} \mathrm{C}$. The solubility products of various iron sulfides were assessed and resulted in consensus values for the pKs (FeS: $3.6 \pm 0.2 ; \mathrm{FeS}_{2} 16.4 \pm 1.2 ; \mathrm{Fe}_{3} \mathrm{~S}_{4} 4.4 \pm$ $0.1 ; \mathrm{Fe}_{7} \mathrm{~S}_{8} 5.1 \pm 0.1$ ). This improved our understanding of the solubility of iron sulfide in both synthetic and natural water at room temperature (Davison, 1991).

\section{Stability}

$\mathrm{FeS}$ is stable within the P-T range of the Martian core (Kavner et al., 2001). Understanding the relationship between the stability of iron sulfide and its chemical environment is of key importance. Once iron sulfide is formed, its structure is reversible. Studies have examined the stability of $\mathrm{FeS}_{2}$ in different temperatures and the concentrations of absorbed water on the surface. Temperature has little effect on the morphology of $\mathrm{FeS}_{2}$ under low absorbed water concentrations. However, at above $90 \mathrm{~K}$, the conversion from an octahedral structure to a cubic shape is promoted. At higher concentrations of water, the dependence on temperature is more apparent (Barnard and Russo, 2009). The latter study established that functions of the surface ligands affect the stability of $\mathrm{FeS}_{2}$ ( $\mathrm{FeS}_{2}$ nanorods synthesized in laboratory) (Barand and Russo, 2009). The stability of FeS contributed to low energy excitation from Fe d to S-S $\sigma^{*}$ p (Zhang et al., 2018). $\mathrm{Fe}_{3} \mathrm{~S}_{4}$ was observed at $200^{\circ} \mathrm{C}$ for $30 \mathrm{~h}$ then it transformed to $\mathrm{FeS}_{2}$ over time (Gao et al., 2015).

\section{Reactivity}

Iron sulfide is highly reactive to $\mathrm{N}_{2}$ and $\mathrm{H}_{2} \mathrm{~S}$. This reaction occurs at room temperature and the adsorption of $\mathrm{N}_{2}$ is dependent on the surface $\mathrm{FeS}$ and on the electronic state of $\mathrm{N}_{2}$. A decrease in absorbed $\mathrm{N}_{2}$ and $\mathrm{H}_{2} \mathrm{~S}$ could be explained by the formation of ammonia (Kasting, 1993). The reactivity of $\mathrm{Fe}_{7} \mathrm{~S}_{8}$ is similar to FeS (Niño et al., 2018). The presence of both $\mathrm{Au}^{1+}$ and $\mathrm{Au}$ atoms has been observed on the surface of $\mathrm{FeS}_{2}$. Au deposition increased at higher $\mathrm{pH}$ and temperatures. The reactivity of $\mathrm{Au}^{1+}$ sulfides with $\mathrm{FeS}_{2}$ have also been investigated (Scaini et al., 1998). The reactivity of $\mathrm{FeS}_{2}$ using gaseous $\mathrm{H}_{2} \mathrm{O}$ and $\mathrm{O}^{2-}$ was similarly reported. Gaseous $\mathrm{H}_{2} \mathrm{O}$ leads to the formation of iron hydroxides on $\mathrm{FeS}_{2}$. A sequence of different exposures also leads to the formation of a range of products $\left(\mathrm{SO}_{4}^{2-}, \mathrm{Fe}(\mathrm{OH})_{3}\right)$ (Usher et al., 2005). Recently, $\mathrm{FeS}_{2}$ was shown to be a potential nanomaterial for prebiotic chemistry due to its highly reactive surface that drives amino acid adsorption (Ganbaatar et al., 2016). Among the most common probes, water molecules have been used to explore 

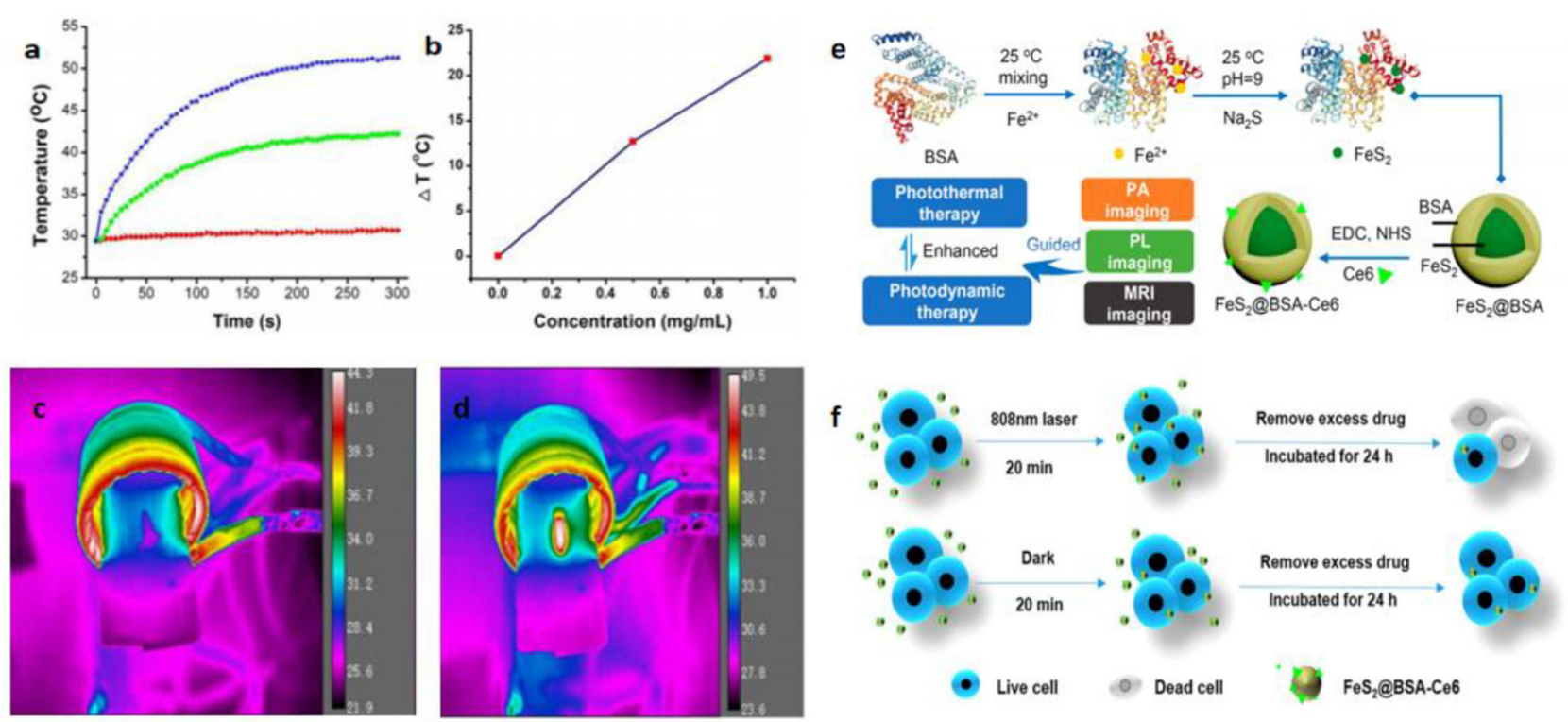

FIGURE 3 | Magnetocaloric conversion performance (a-d) and photothermal property of iron sulfides. (a) Temperature change of the Fe $\mathrm{S}_{4}$ nanoparticles in water at varied concentrations of $\mathrm{Fe}^{2+}$ (i.e., $0,0.5$, and $1.0 \mathrm{mg} / \mathrm{mL}$ ) as a function of magnetic field action time. (b) Plot of temperature change over 300 s vs. the concentration of $\mathrm{Fe}_{3} \mathrm{~S}_{4}$ nanoparticles. Thermal imaging of (c) pure water and (d) $\mathrm{Fe}_{3} \mathrm{~S}_{4}$ nanoparticles $(1.0 \mathrm{mg} / \mathrm{mL})$ under the action of an AMF for 5 min. Reproduced with permission from Fu et al. (2019). Copyright 2019, Frontiers in Materials. (e) Synthetic route and applications of FeS 2 nanodots in the base of its photothermal activity. (f) Scheme showing photothermal enhanced cellular uptake of FeS ${ }_{2} @ B S A-C e 6$ nanoparticles. Reproduced with permission from Jin et al. (2018). Copyright 2017, American Chemical Society.

the reactivity of $\mathrm{FeS}_{2}$ (De Leeuw et al., 2000). The different phases of iron sulfide display a wide range of reactivities to chlorinated solvents. Conditions including $\mathrm{pH}$, sulfide concentrations, metal ions, and natural organic matter can affect the reaction kinetics of the degradation of chlorinated solvents (He et al., 2015). The interaction of $\mathrm{FeS}, \mathrm{Fe}_{3} \mathrm{~S}_{4}$ and $\mathrm{CO}_{2}$ have also been reported. The charge transfer on FeS can also effectively activate $\mathrm{CO}_{2}$, whilst $\mathrm{Fe}_{3} \mathrm{~S}_{4}$ is unreactive to $\mathrm{CO}_{2}$ (SantosCarballal et al., 2017).

\section{Magnetic Properties}

Nanomaterials with magnetic properties have numerous applications, including magnetocaloric therapies, as MRI agents, magnetic separation materials, and magnetic carriers. The discovery of their magnetic properties led to the identification of iron sulfide phases. The ferromagnetism of $\mathrm{Fe}_{7} \mathrm{~S}_{8}$ can be explained by $\mathrm{Fe}^{3+}$ ions with excess sulfur (Yosida, 1951). The magnetic susceptibility $\chi$ of natural $\mathrm{FeS}_{2}$ was found to be $64 \times$ $10^{-6} 68 \times 10^{-6} \mathrm{~cm}^{3}$ /moles between 4.2 and $380 \mathrm{~K}$ (Mohindar and Jagadeesh, 1979). Magnetic ordering in FeS was inferred and used to prove strong itinerant spin fluctuations. FeS can also be used as a superconductor (Kwon et al., 2011). Even when the structure of FeS is changed from troilite to the MnP-type under high pressure, the antiferromagnetic properties are preserved until the monoclinic structure is formed (Ono, 2007). The magnetic moment then disappears and yetragonal-phase FeS (Tc: $5 \mathrm{~K})$ was observed for the same structure as the superconductor FeSe (Tc: $8 \mathrm{~K}$ ) (Kuhn et al., 2016). $\mathrm{Fe}_{3} \mathrm{~S}_{4}$ displays high Mrs/ $\chi$, $(\mathrm{Mrs} / \chi$ : the saturation isothermal remnant magnetization: magnetic susceptibility) and its MrsMs (hysteresis ratios) and $\mathrm{Bcr} / \mathrm{Bc}$ are 0.5 and 1.5 (Ms: saturation magnetization; $\mathrm{Bc}$ : the coercive force; Bcr: the coercivity of remanence). $\mathrm{Fe}_{3} \mathrm{~S}_{4}$ also displays unique high-temperature properties, with a clear drop in magnetization from 270 to $350^{\circ} \mathrm{C}$ (Roberts, 1995). Synthesized $\mathrm{Fe}_{3} \mathrm{~S}_{4}$ contains various crystals from small superparamagnetic grains (non-remanence) to large multi-domain grains (Snowball, 1991). The magnetic hysteresis properties of $\mathrm{Fe}_{7} \mathrm{~S}_{8}$ have also been studied (Menyeh and O'Reilly, 1997). The relationship between structure and magnetic properties has been reported within variable temperatures. Magnetic transitions occurred within the transformation of the structure (Powell et al., 2004). The magnetocaloric conversion ability of $\mathrm{Fe}_{3} \mathrm{~S}_{4}$ nanoparticles has been measured under an alternating magnetic field (AMF). Meanwhile, the excellent physical and chemical properties provide magnetothermal thrombolytic ability in medical applications (Fu et al., 2019; Figure 3).

\section{Photothermal Properties}

Photothermal therapy (PTT) has attracted considerable attention in recent years. The mechanism of PTT results mainly from photo-absorbing nanomaterials that generate heat through continuous laser irradiation, destroying cancer cells, but causing no damage to healthy tissue. It is therefore necessary to pay attention to the photothermal properties of iron sulfide. PEGylated FeS (FeS-PEG) nanoplates exhibit high near infrared (NIR) absorbance. Using Infrared (IR) thermal imaging, the 


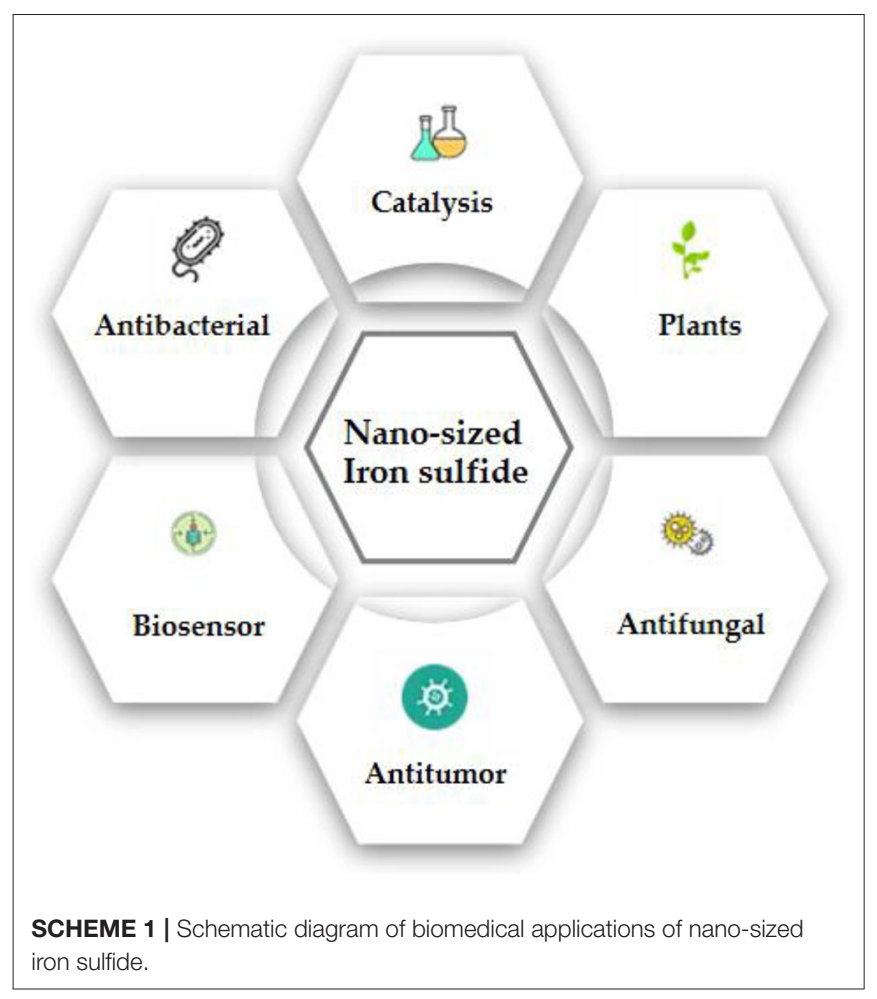

temperature can reach $70^{\circ} \mathrm{C}$ within $5 \mathrm{~min}$. Meanwhile, FeSPEG displays stronger photothermal conversion efficiency than other known iron oxides (Yang et al., 2015). Ultrasmall $\mathrm{FeS}_{2}$ nanodots have also been synthesized and have been shown to be useful for photodynamic therapy. Chlorin e6 (Ce6) was used to conjugate $\mathrm{FeS}_{2}$ in the presence of the template bovine serum albumin (BSA). FeS $2 @ B S A-C e 6$ nanodots $(7 \mathrm{~nm})$ demonstrated good results in in vivo photoacoustic (PA) imaging, MRI and enhanced cellular uptake (Jin et al., 2018; Figure 3).

\section{Biomedical Applications}

To-date, a variety of biomedical applications of iron sulfide (catalysts, antibacterial agents, cancer therapies, drug delivery systems, thrombolytic agents, biosensors, antifungal agents, seed improvers in phyto-applications) and their functional mechanisms have been summarized (Scheme 1).

\section{Enzyme-Like Catalysis}

Iron sulfur clusters are critical cofactors in many enzymes and proteins which conduct redox reactions and regulate oxidative stress. Thus, nano-sized iron sulfides are expected to perform similar catalysis and act as nanozymes. Previous studies have shown that iron sulfide can effectively activate persulfate (PS) or peroxymonosulfate (PMS) to generate sulfate radicals (Xiao et al., 2020). Other common reactions involving iron sulfide are shown in section Sonochemical Synthesis. Since iron oxide nanoparticles were shown to possess intrinsic peroxidase activity in 2007 (Gao et al., 2007), it has been speculated that iron sulfide has similar properties. The catalytic processes of iron sulfide are shown in Figure 4. High catalytic activity, multi-enzymes activities, harsh environmental resistance, storage stability, and the intrinsic advantages of nanomaterials provide further possibilities for biomedicine development, meaning that good alternatives to natural enzymes exist. The enzymatic activity of iron sulfide has been intensely investigated. In 2010, FeS nanosheets were reported to possess peroxidase-like activity. FeS suspensions were shown to catalyze the oxidation of peroxidase substrates, 3, 3', 5, 5'-Tetramethylbenzidine (TMB) to produce a blue product in the presence of $\mathrm{H}_{2} \mathrm{O}_{2}$ (Dai et al., 2009) (Figure 4). $\mathrm{Fe}_{7} \mathrm{~S}_{8}$ nanowires' also possessing intrinsic peroxidase activity was also reported in 2013 for which catalytic behavior was observed. The apparent $\mathrm{K}_{M}$ of $\mathrm{Fe}_{7} \mathrm{~S}_{8}$ with $\mathrm{TMB}$ as a substrate was $0.548 \mathrm{mM}$, almost six times lower than that of horseradish peroxidase (HRP). These results demonstrate that $\mathrm{Fe}_{7} \mathrm{~S}_{8}$ has a higher affinity to TMB than to HRP (Yao et al., 2013). In 2015, magnetic $\mathrm{Fe}_{3} \mathrm{~S}_{4}$ NPs was shown to possess peroxidaselike activity. Through investigating steady state kinetics, $\mathrm{Fe}_{3} \mathrm{~S}_{4}$ was shown to possess a higher affinity for $\mathrm{H}_{2} \mathrm{O}_{2}$ than HRP. The reasons could be that $\mathrm{Fe}_{3} \mathrm{~S}_{4}$ binds to and reacts with $\mathrm{H}_{2} \mathrm{O}_{2}$, following which nanozyme is released prior to reacting with the second substrate TMB (Ding et al., 2016). nFeS $\left(\mathrm{Fe}_{1-\mathrm{x}} \mathrm{S}\right.$ and $\mathrm{Fe}_{3} \mathrm{~S}_{4}$ ) (detailed description in section Hydrothermal Synthesis) have been shown to possess both peroxidase-like and catalaselike activity (Figure 4). nFeS is able to decompose $\mathrm{H}_{2} \mathrm{O}_{2}$ into free radicals and $\mathrm{O}_{2}$, promoting the release of polysulfanes (Xu et al., 2018). $\mathrm{FeS}_{2}$ has also been shown to possess amylase-like properties (Srivastava et al., 2014b).

\section{Antibacterial Alternatives}

Schoonen et al. reported on the antibacterial action of $\mathrm{FeS}_{2}$. Its mechanism was shown to be related to the formation of $\mathrm{H}_{2} \mathrm{O}_{2}$. The same group also reported how minerals can induce the formation of reactive oxygen species (Cohn et al., 2006; Schoonen et al., 2006). The rapid absorption of $\mathrm{Fe}^{2+}$ can influence bacterial metabolism. The oxidization of $\mathrm{Fe}^{2+}$ to $\mathrm{Fe}^{3+}$ leads to reactive oxygen species (ROS) production and biomolecular damage. As a result, iron sulfide can act as antimicrobial agents. Iron sulfides have been reported to be effective in bacterial infections. In 2013, He et al. reported on the bacteriostatic activity of $\mathrm{Fe}_{3} \mathrm{~S}_{4} / \mathrm{Ag}$ against E. coli (86.2\%) and S. aureus (90.6\%). Meanwhile, $\mathrm{Fe}_{3} \mathrm{~S}_{4}$ NPs without Ag have no effect (He et al., 2013). The Arenas-Arrocena group synthesized $\mathrm{Fe}_{\mathrm{x}-1} \mathrm{~S}$ NPs and reported their antibacterial and cytotoxic activity in 2018. Antibacterial activity against $S$. aureus, E. coli and E. faecalis was observed (Argueta-Figueroa et al., 2018). In addition, Gao and coworkers discovered antibacterial inorganic iron polysulfides materials that were converted by organosulfur compounds in 2018. Inorganic nano-sulfides ( $\mathrm{nFeS}, \mathrm{Fe}_{1-\mathrm{x}} \mathrm{S}$, and $\mathrm{Fe}_{3} \mathrm{~S}_{4}$ ) have shown inhibition against Pseudomonas aeruginosa and Staphylococcus aureus. These studies also described new strategies to synthesize iron sulfide nanomaterials. Furthermore, the S. mutans biofilmrelated infections could be prevented by nFeS (Xu et al., 2018) (Figure 5). The antibacterial properties of $\mathrm{FeS}_{2}-\mathrm{Bi}_{2} \mathrm{O}_{3}$ against the pathogenic microorganisms Mycobacterium tuberculosis and Salmonella have also been measured (Manafi et al., 2019). Diksha et al. reported that FeS NPs could enhance intrabacterial ROS levels in bacteria by light irradiation in 2020. This was revealed 


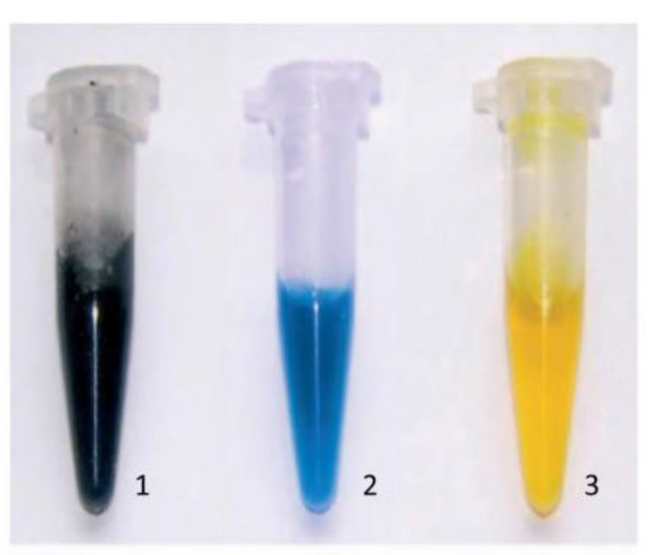

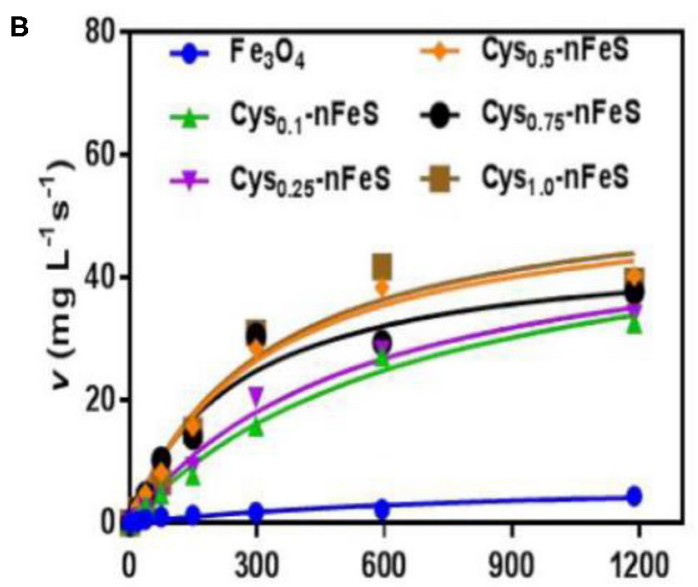

FIGURE 4 | Schematic diagram of catalysis of iron sulfide as a nanozyme. (A) The peroxidase-like activity of FeS. Images of the suspension of sheet-like FeS nanostructure (1), mixture of TMB and $\mathrm{H}_{2} \mathrm{O}_{2}$ after catalytic reaction by sheet-like FeS nanostructure (2), mixture of TMB and $\mathrm{H}_{2} \mathrm{O}_{2}$ after adding $\mathrm{H}_{2} \mathrm{SO}_{4}$ to quench the catalytic reaction by sheet-like FeS nanostructure (3). Reproduced with permission from Dai et al. (2009). Copyright 2009, Wiley-VCH Verlag GmbH \& Co. KGaA, Weinheim. (B) The catalase-like activity of Cys-nFeS. The trend of KM and the ratio of Vmax/KM in the kinetics assay with varied cysteine. Reproduced with permission from Xu et al. (2018). Copyright 2018, Nature Publishing Group.

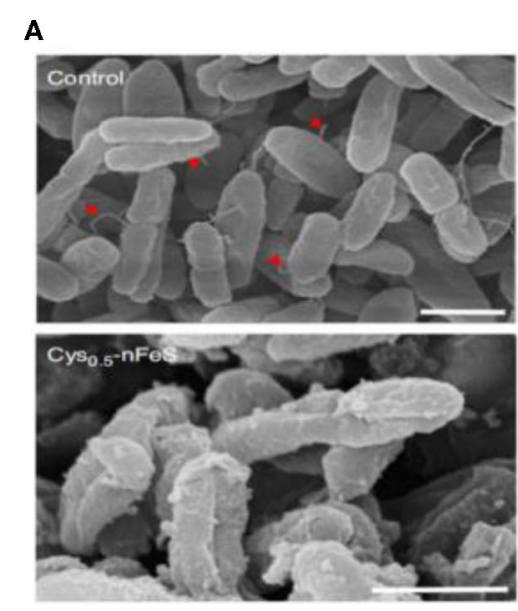

D

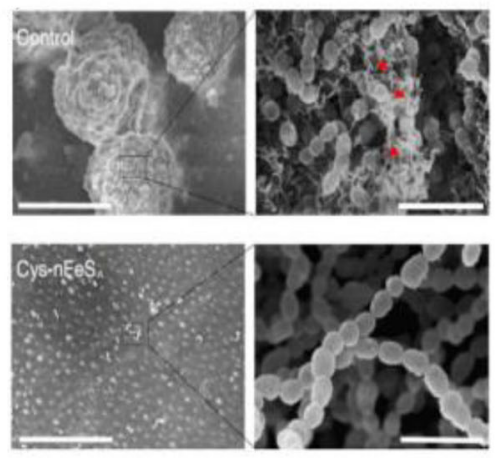

B
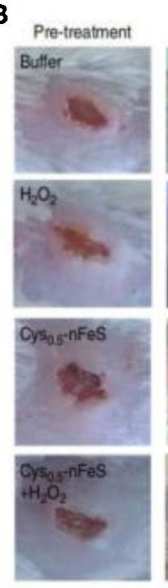

E

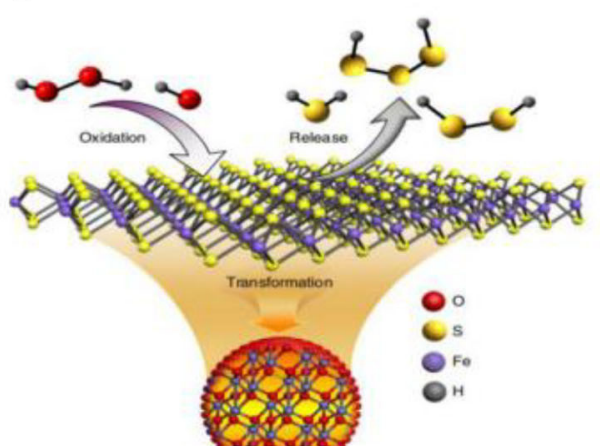

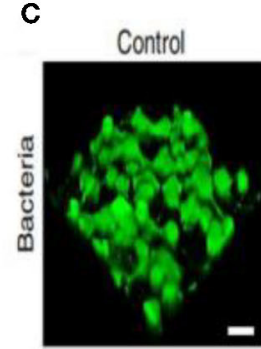
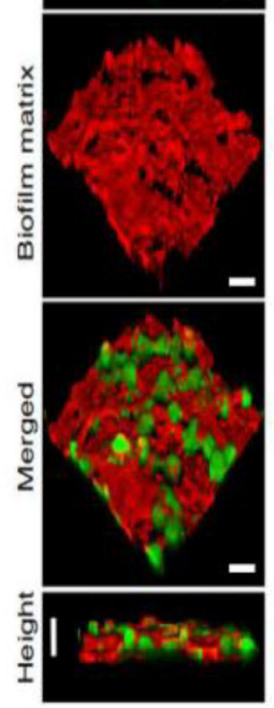
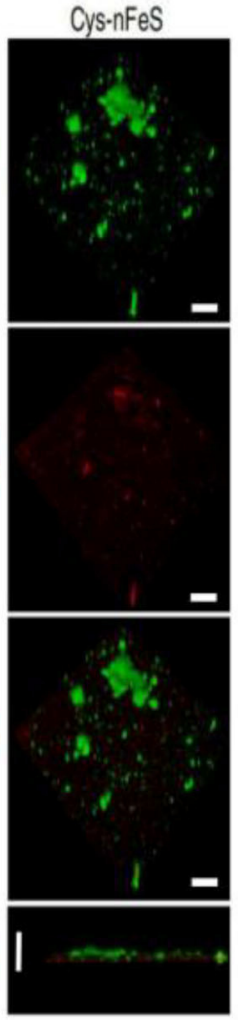

FIGURE 5 | (A) Morphology of $P$. aeruginosa before (control) and after Cys-nFeS treatment. The red triangles indicate flagella. Scale bars: $1 \mu \mathrm{m}$. (B) Photographs of $P$. aeruginosa infected wounds treated with buffer (control), Cys-nFeS, $\mathrm{H}_{2} \mathrm{O}_{2}$, and Cys-nFeS $+\mathrm{H}_{2} \mathrm{O}_{2}$ at different times (five mice in each group). (C) Confocal 3D image of a S. mutans UA159 biofilm treated by Cys-nFeS. Scale bars: $100 \mu \mathrm{m}$. (D) SEM image of a S. mutans biofilm treated by Cys-nFeS. The red arrows indicate EPS. Left scale bars: $100 \mu \mathrm{m}$. Right scale bars: $3 \mu \mathrm{m}$. (E) Scheme of polysulfane release from nFeS. Reproduced with permission from Xu et al. (2018). Copyright 2018, Nature Publishing Group. 

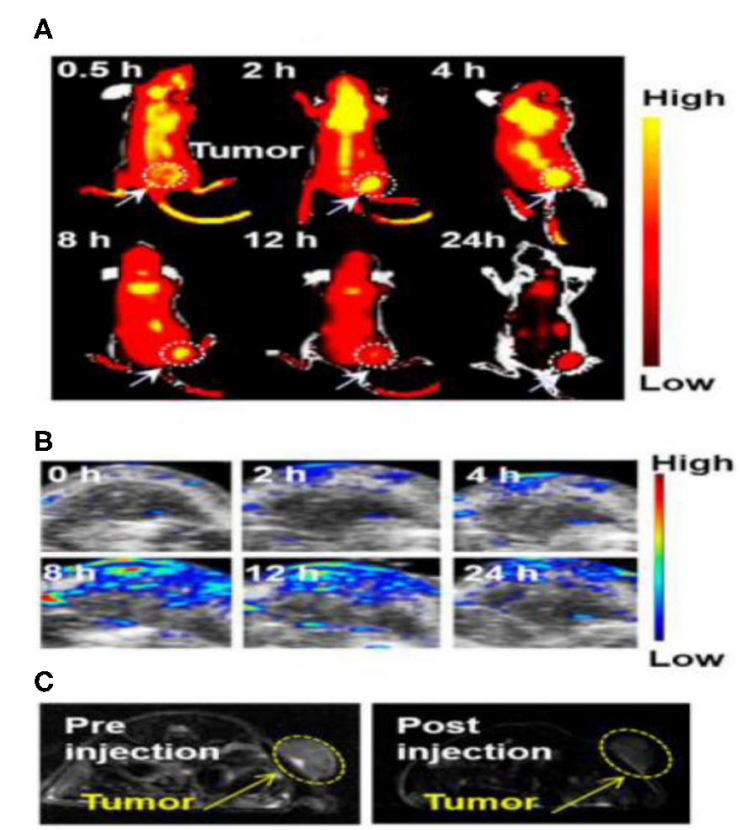

D

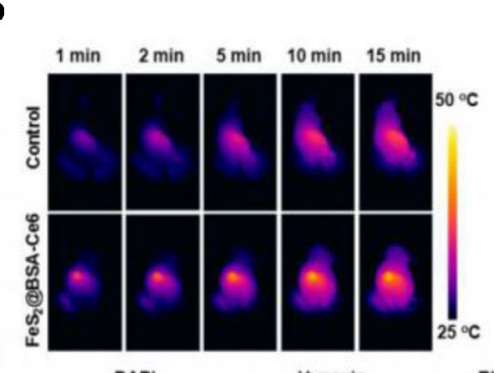

F

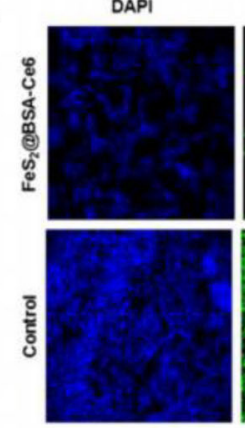

Hypoxia
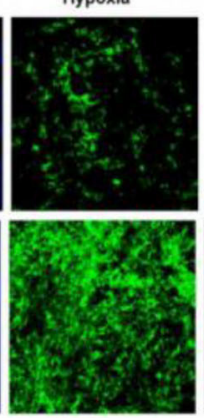

E
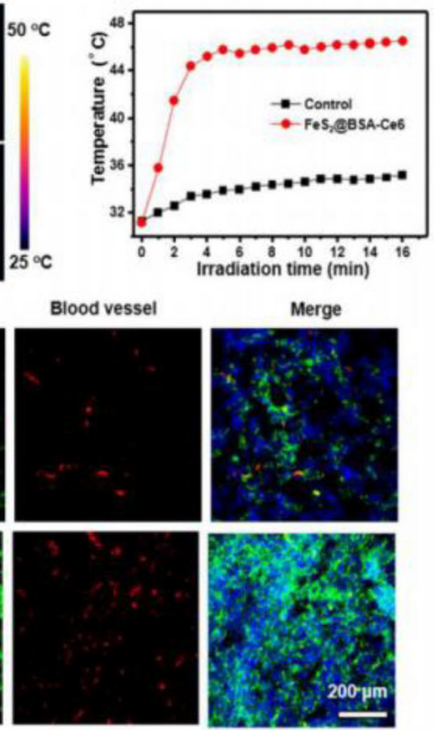

FIGURE 6 | (A) In vivo fluorescence images of 4T1 tumor-bearing nude mice taken at different time points post iv injection of FeS 2 @BSA-Ce6 nanodots (3.5 mg/kg $\mathrm{Ce} 6$ and $12 \mathrm{mg} / \mathrm{kg} \mathrm{FeS}$ ). (B) Photoacoustic images of tumors in mice taken at different time points post iv injection of FeS $\mathrm{BBSA} \mathrm{BSe} 6$ nanodots. (C) MR images of 4T1 tumor-bearing nude mice before and $8 \mathrm{~h}$ after iv injection of FeS $\mathrm{F}_{2} @ \mathrm{BSA}-\mathrm{Ce} 6$ nanodots. (3.5 mg/kg Ce6 and 12 mg/kg FeS $)$. (D) IR thermal images of tumors in mice iv injected with FeS $2 @ B S A-C e 6$ under $808 \mathrm{~nm}$ laser irradiation (0.8W/cm², $15 \mathrm{~min})$. (E) Surface temperature changes of tumors monitored by the IR thermal camera during laser irradiation. (F) Representative immunofluorescence images of tumor slices after hypoxia staining. The cell nucleus, hypoxia areas, and blood vessels were stained with DAPI (blue), antipimonidazole antibody (green), and anti-CD31 antibody (red), respectively. Reproduced with permission from Jin et al. (2018). Copyright 2017, American Chemical Society.

as the primary antibacterial mechanism of FeS NPs (Agnihotri et al., 2020).

\section{Cancer Therapy}

Chen and colleagues reported that tumors in mice could disturb iron metabolism in the major organs. The chemical form of iron in the tumors was ferrous-sulfide-like iron and ferritin, highlighting the potential of iron sulfide for cancer treatment (Chen and Chen, 2017). Chang et al. synthesized $\mathrm{Fe}_{3} \mathrm{~S}_{4}$ particles with magnetic properties through co-precipitation. The NPs were used for cancer hyperthermia providing a new avenue for multimodal anticancer therapies (Chang et al., 2011). In 2015, Yang et al. concluded that triangle nanoplates (FeS/PEG nanostructures) could be used as nanoagents for in vivo MRIguided photothermal cancer treatment. High doses of FeS nanoplates were shown to be safe and effective in mice. This study highlighted the potential clinical use of FeS, for MRI in addition to PTT (Figure 6) (Yang et al., 2015). In 2018, $\mathrm{Fe}_{3} \mathrm{~S}_{4}$ nanosheets were shown to possess high efficiencies for MRI guided photothermal and chemodynamic synergistic therapy, opening up a new direction for the design of inorganic iron sulfide for future clinical applications (Guan et al., 2018). Tiny nano-sized iron sulfide with simple biomineralization method has also been attention owing to its huge potential in vivo application especially in cancer therapy combined with its excellent photothermal and magnetic performance. FeS $2 @ B S A-$ Ce6 (detailed in section Biomineralization) exhibited good results whether in vivo multimodal imaging or in vivo combined therapy (Jin et al., 2018). Meanwhile, the latest literature proved 3 nm FeS@BSA QDs could be used as T1-weighted MRI contrast agents. Moreover, the ultrasmall QDs showed good results in photothermal therapy and they could be cleared via glomerular filtration into bladder after treatment (Yang et al., 2020). The use of iron chalcogenides has also been investigated. $\mathrm{Cu}_{5} \mathrm{FeS}_{4}{ }^{-}$ PEG NPs were effective in dual-modal imaging and PTT (Zhao et al., 2016). In 2017, $\mathrm{CuFeS}_{2}$ nanoplates were used for in vivo photothermal/photoacoustic imaging and cancer chemotherapy/PTT (Ding et al., 2017).

\section{Drug Delivery}

Iron sulfide holds utility as a drug carrier. In previous studies, modified $\beta$-cyclodextrin ( $\beta$-CD) and PEG $\mathrm{Fe}_{3} \mathrm{~S}_{4}$ (GMNCs) were used as drug loading NPs. Both $\beta-\mathrm{CD}$ and PEG have been used to control the shape and size of GMNCs as surfactants. In addition, the biocompatibility of $\mathrm{Fe}_{3} \mathrm{~S}_{4}$ is enhanced, with entrapment efficiencies of $58.7 \%$ for the modified delivery of the chemotherapeutic drug doxorubicin. Meanwhile, the enhanced chemotherapeutic treatment of mouse tumors was obtained through the intravenous injection of doxorubicin (Dox) loaded GMNCs (Feng et al., 2013; Figure 7). 
A

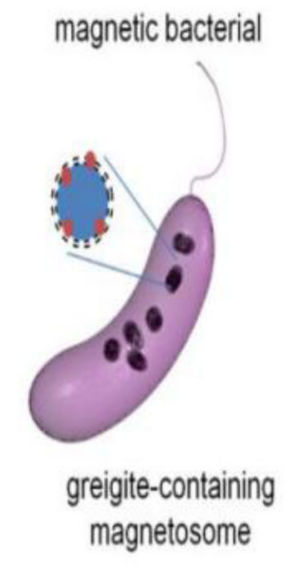

magnetosome-like GMNCs

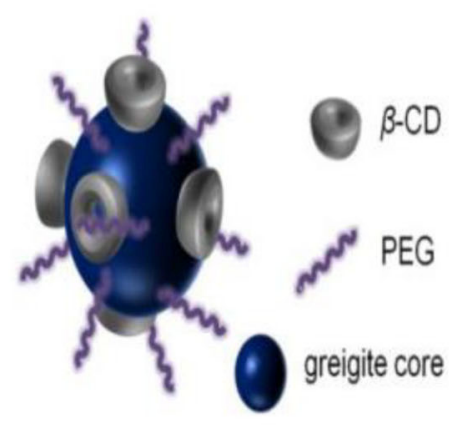

B

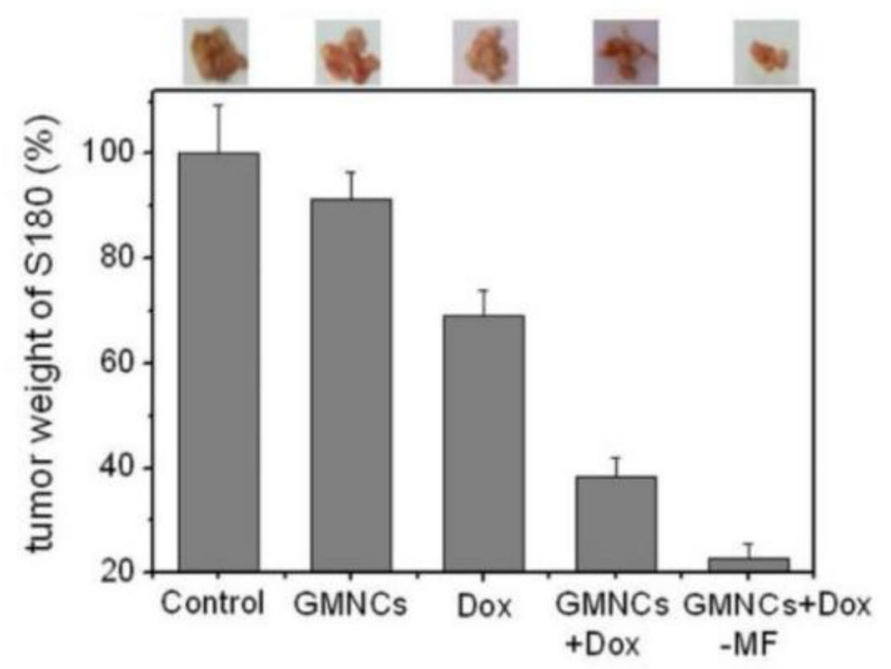

FIGURE 7 | (A) Schematical illustration of the greigite-containing magnetosome and the chemical synthesized magnetosome-like GMNCs. (B) Growth inhibition effect in murine S180 sarcoma model of the sample. The photos and weight ratios of tumor tissue from mice treated with normal saline (control group), GMNCs, Dox at low concentration, and GMNCs loading with Dox (without and with the guidance of external magnetic field), respectively. Reproduced with permission from Feng et al. (2013). Copyright 2013, Nature Publishing Group.

A

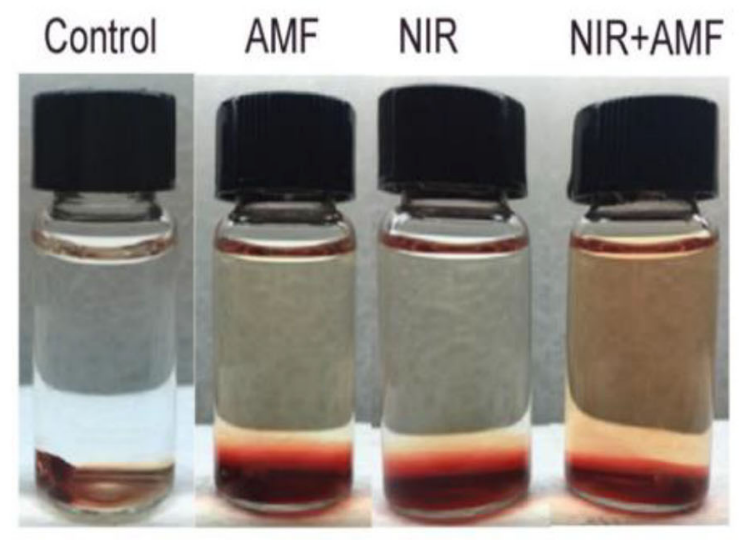

B

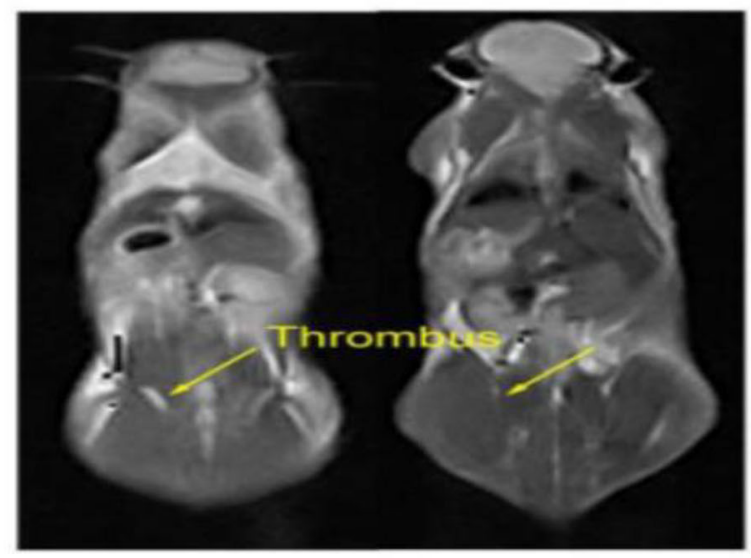

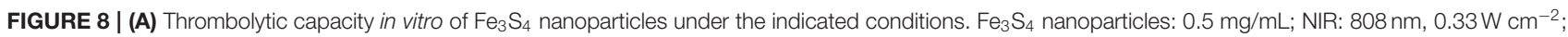
AMF: $4.2 \times 10^{9} \mathrm{~A} \mathrm{~m}^{-1} \mathrm{~s}^{-1}$. (B) T2-weighted MR imaging in vivo of a mouse with celiac vein thrombosis before (left) and after (right) an intravenous injection of a solution of the $\mathrm{Fe}_{3} \mathrm{~S}_{4}$ nanoparticles followed by the simulation of AMF. Reproduced with permission from Fu et al. (2019). Copyright 2019, Frontiers in Materials.

\section{Thrombolytic Agents}

In studies of vascular disease, the removal of thrombosis through non-invasive methods is challenging. However, studies regarding iron sulfide NPs as thrombolytic agents have been reported. Ge et al. first highlighted the utility of $\mathrm{Fe}_{3} \mathrm{~S}_{4} \mathrm{NPs}$ as thrombolytic agents with both photothermal and magnetothermal thrombolytic capability. Using $\mathrm{Fe}_{3} \mathrm{~S}_{4}$ nanoparticles, celiac vein thrombosis could be prevented using magnetic hyperthermia combined PTT. Both in vivo and in vitro, $\mathrm{Fe}_{3} \mathrm{~S}_{4}$ has demonstrated beneficial effects for the removal of thrombi (Figure 8), providing a novel hyperthermia strategy for the prevention of thrombosis (Fu et al., 2019).

\section{Biosensors}

Iron sulfides have been used as glucose sensors due to their intrinsic peroxidase-like activity (Dai et al., 2009). Glucose sensors can be developed using colorimetric methods in which cascade reactions form the core mechanism of glucose detection. TMB could be oxidized to oxTMB in the presence of glucose, GOx and iron sulfide. $\mathrm{H}_{2} \mathrm{O}_{2}$ produced by the decomposition 

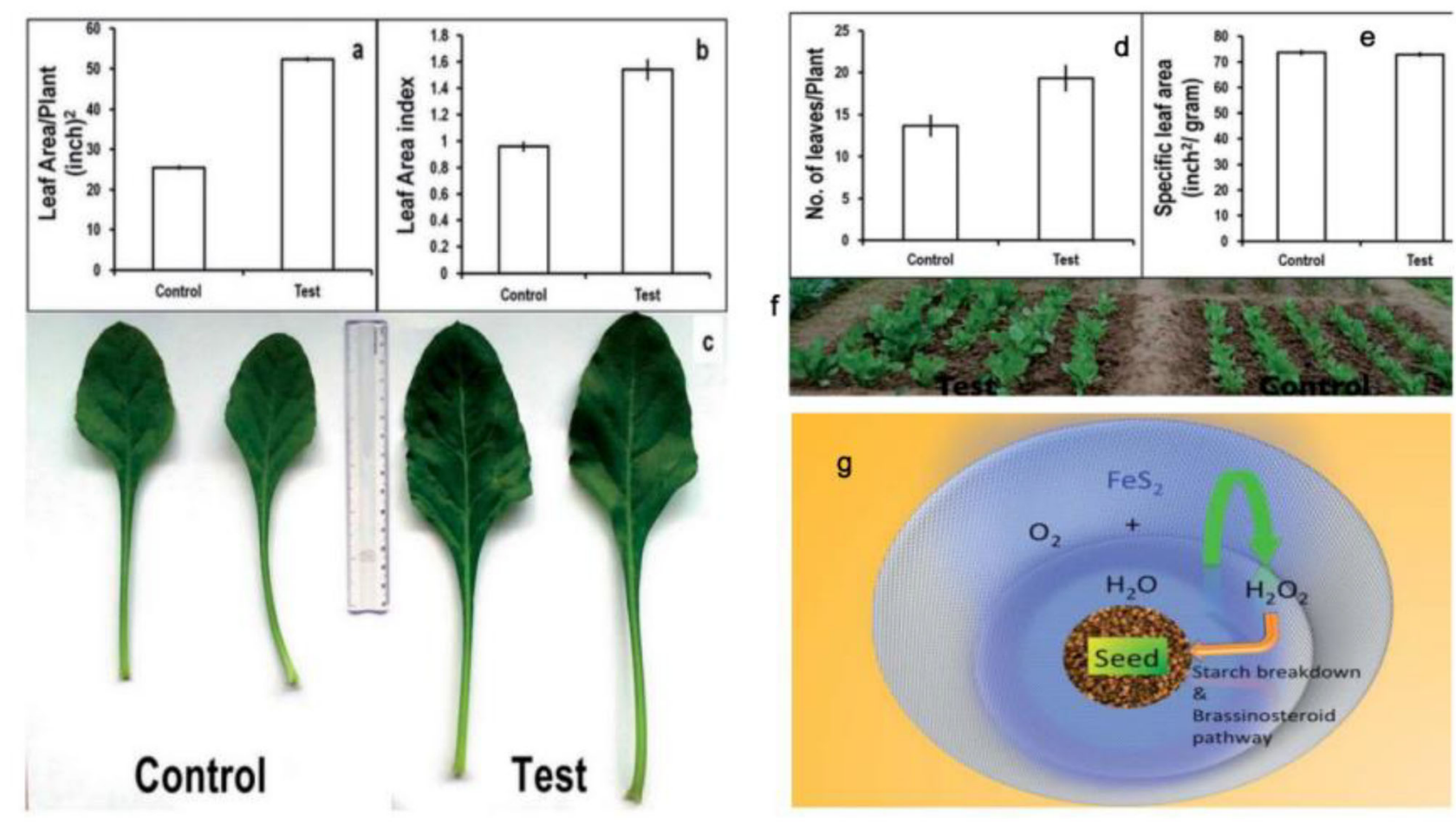

FIGURE 9 | Plant growth parameters: control vs. test $\left(\mathrm{FeS}_{2}\right)$. (a) Leaf area/Plant, showing significant increase in leaf area/test plants (52.4 \pm 0.3$)$ as compared to control (25.6 \pm 0.2). (b) Leaf area index signifying total photosynthetic area available to plant and high values for test samples (1.5 \pm 0.07$)$ can be correlated with high biomass content of pro-fertilized spinach plants in comparison with (0.9 \pm 0.02$)$. (c) Comparative photograph of leaves showing larger leaf area in test plants as compared to control plants. Plant growth parameters: control vs. test (FeS 2 ). (d) Number of leaves/Plant: control: $13 \pm 1.0$; test: $19 \pm 1.0$. (e) Specific leaf area signifies leaf thickness and was found similar for both test and control samples. (f) Field photograph taken at day 50 (just before harvesting the crop) depicting that the test group plants have comparatively more foliage as compared to the control plants. (g) Proposed outline of the mechanism of action of FeS 2 on spinach seed in enhancing germination and plant growth. Reproduced with permission from Srivastava al. (2014). Copyright 2014, The Royal Society of Chemistry.

of glucose in the presence of glucose oxidase can be used as a substrate for iron sulfide. Iron sulfide peroxidase-like mimics can oxidize TMB to oxTMB in the presence of $\mathrm{H}_{2} \mathrm{O}_{2} \cdot \mathrm{Fe}_{7} \mathrm{~S}_{8}$ nanowires also possess peroxidase activity. Using a linear range, glucose concentrations of $5 \times 10^{-6}$ to $5 \times 10^{-4} \mathrm{M}$ could be detected (Yao et al., 2013). In 2016, Xian and colleagues used $\mathrm{Fe}_{3} \mathrm{~S}_{4}$ magnetic nanoparticles (MNPs) to quantify glucose concentrations in human serum. A linear range was measured from 2 to $100 \mu \mathrm{M}$, and the limit of detection (LOD) was $0.16 \mu \mathrm{M}$ (Ding et al., 2016). These studies highlighted the potential of as-prepared iron sulfide as both glucose sensors and artificial peroxidase nanozymes.

\section{Antifungal Agents}

In vitro antifungal FeS NPs exhibited significant anti-fungal activity against $F$. verticillioides at $18 \mu \mathrm{g} \mathrm{ml}^{-1}$, with a higher efficiency than standard fungicides (carbendazim (median effective dose (ED50): $230 \mu \mathrm{g} \mathrm{ml}^{-1}$ ). These were the first reports highlighting the antifungal activity of iron sulfide. The influence of FeS on both seed health and quality parameters of rice was also evaluated based on this antifungal activity. Iron sulfides were shown to be effective in iron deficient soils as an alternative to high dose organic fungicides (Ahuja et al., 2019).

\section{Seed Improvements in Phyto-Applications}

$\mathrm{FeS}_{2}$ represents a photovoltaic material, which increases plant biomass in the seeds of chickpeas (Cicer arietinum). Meanwhile, the mechanism of functional $\mathrm{FeS}_{2}$ is attributed to its amylase-like activity. In the presence of $\mathrm{H}_{2} \mathrm{O}$ and $\mathrm{FeS}_{2}$, starch in the seeds can be broken down to $\mathrm{H}_{2} \mathrm{O}_{2}$, which participates in the absorption of $\mathrm{CO}_{2}$ and improves plant health. Spinach seeds treated with $\mathrm{FeS}_{2}$ exhibited broader leaf morphologies, larger leaf numbers and an increased biomass (Srivastava et al., 2014b) (Figure 9). In later studies, seed priming with $\mathrm{FeS}_{2}$ was reported as an innovative strategy (Das et al., 2016). FeS 2 also improved both seed yield and growth in the Brassica juncea field (Rawat et al., 2017).

\section{CONCLUSIONS}

In summary, we have highlighted the most recent methods of nano-iron sulfide synthesis, including nano iron sulfide modifications and characterizations. Strikingly, nano-sized iron sulfides demonstrate versatile physiochemical properties, 


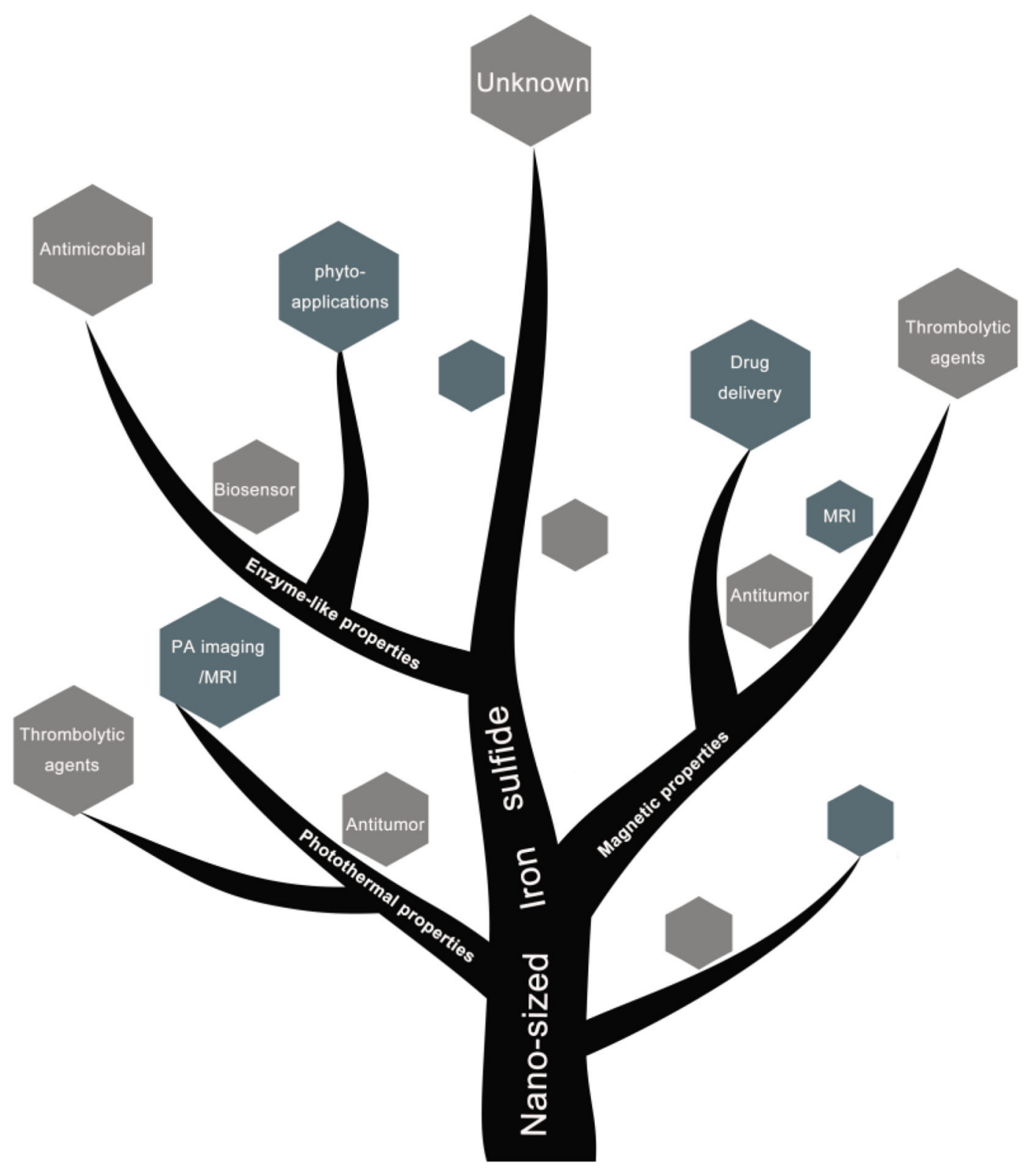

SCHEME 2 | Schematic diagram of biomedical applications based on physiochemical properties of nano-sized iron sulfide.

enzyme-like catalysis, high stability and biocompatibility, which facilitate their biomedical applications. A range of nano-iron sulfides have been assessed in catalysis, tumor therapy, antibacterials and antifungals, drug delivery, biosensors, thrombus removal and in plants. Their advantages include (1) high biocompatibility due to the key role of iron and sulfur in natural life; (2) the photothermal and magnetic properties of nano-sized iron sulfide; (3) their nanostructure and large surface area that can improve drug delivery; and (4) their enzyme-like properties as nanozymes, including their high reactivity to numerous chemical substances that can regulate hydrogen peroxide, ROS and various catalytic reactions to treat related diseases.

Although it has been shown that nano-sized iron sulfides represent great potential in numerous applications in biomedicine (Scheme 2), a number of issues remain to be addressed, including the synthesis of iron sulfide that is stable and in a single phase, with modifications to adapt to the biological environment. Studies have found that the modification of molecular CTAB inhibits the preparation of $\mathrm{Fe}_{3} \mathrm{~S}_{4}$ NPs due to competitive inhibition with $\mathrm{Na}_{2} \mathrm{~S}$ under acidic conditions, resulting in the formation of non-magnetic iron sulfides and 
other byproducts. Citrate modified nanoparticles have not sufficient particle spacing due to aggregation effects (Simeonidis et al., 2016). In addition, the biomedical assessments of iron sulfides remain sparse, and their mechanisms of action under physiological conditions are poorly understood. The intrinsic enzyme-like properties of iron sulfide as nanozymes may provide a window to understand its biological effects and potential cytotoxicity in vivo. Taken together, nano-sized iron sulfides possess versatile physiochemical properties and enzyme-like properties, which describe a form of distinctive nanomaterials with great potential for use in biomedical applications.

\section{REFERENCES}

Agnihotri, S., Mohan, T., Jha, D., Gautam, H., and Roy, I. (2020). Dual Modality FeS Nanoparticles with Reactive Oxygen Species-Induced and Photothermal Toxicity toward Pathogenic Bacteria. ACS OMEGA 5, 597-602. doi: 10.1021/acsomega.9b03177

Ahuja, R., Sidhu, A., and Bala, A. (2019). Synthesis and evaluation of iron(ii) sulfide aqua nanoparticles (FeS-NPs) against Fusarium verticillioides causing sheath rot and seed discoloration of rice. Eur. J. Plant Pathol. 155, 163-171. doi: $10.1007 /$ s10658-019-01758-3

Argueta-Figueroa, L., Martinez-Alvarez, O., Santos-Cruz, J., Garcia-Contreras, R., Acosta-Torres, L. S., Fuente-Hernández, J., et al. (2017). Nanomaterials made of non-toxic metallic sulfides: a systematic review of their potential biomedical applications. Mater. Sci. Eng. C 76, 1305-1315. doi: 10.1016/j.msec.2017.02.120

Argueta-Figueroa, L., Torres-Gómez, N., García-Contreras, R., Vilchis-Nestor, A. R., Martínez-Alvarez, O., Acosta-Torres, L. S., et al. (2018). Hydrothermal synthesis of pyrrhotite $\left(\mathrm{Fe}_{\mathrm{x}-1} \mathrm{~S}\right)$ nanoplates and their antibacterial, cytotoxic activity study. Progress Nat. Sci. 28, 447-455. doi: 10.1016/j.pnsc.2018.06.003

Barand, A., and Russo, S. (2009). Modeling the environmental stability of $\mathrm{FeS}_{2}$ nanorods, using lessons from biomineralization. Nanotechnology 20:115702. doi: 10.1088/0957-4484/20/11/115702

Barnard, A., and Russo, S. (2009). Morphological stability of Pyrite $\mathrm{FeS}_{2}$ nanocrystals in water. J. Phys. Chem. C 113, 5376-5380. doi: 10.1021/jp809377s

Beal, J., Etchegoin, P., and Tilley, R. (2012). Synthesis and characterisation of magnetic iron sulfide nanocrystals. J. Solid State Chem. 189, 57-62. doi: 10.1016/j.jssc.2012.01.015

Bi, Y., Yuan, Y., Exstrom, C. L., Darveau, S. A., and Huang, J. (2011). Air stable, photosensitive, phase pure iron pyrite nanocrystal thin films for photovoltaic application. Nano Letter 11, 4953-4957. doi: 10.1021/nl202902z

Chang, Y., Savitha, S., Sadhasivam, S., Hsu, C., and Lin, F. (2011). Fabrication, characterization, and application of greigite nanoparticles for cancer hyperthermia. J. Colloid Interface Sci. 363, 314-319. doi: 10.1016/j.jcis.2010.06.069

Chen, R., and Chen, G. (2017). Tumor-induced disorder of iron metabolism in major organs: a new insight from chemical speciation of iron. J. Int. Med. Res 46, 70-78. doi: $10.1177 / 0300060517718711$

Chen, B., and Gu, N. (2017). Current status and development of pharmaceutical iron based nanomaterials. Mater. China 36, 211-218.

Cohn, C., Laffers, R., Simon, S., O'Riordan, T., and Schoonen, M. (2006). Role of pyrite in formation of hydroxyl radicals in coal: possible implications for human health. Part. Fibre Toxicol. 3:16. doi: 10.1186/1743-8977-3-16

Dai, Z., Liu, S., Bao, J., and Ju, H. (2009). Nanostructured FeS as a mimic peroxidase for biocatalysis and biosensing. Chem. Eur. J. 15, 4321-4326. doi: $10.1002 /$ chem. 200802158

Das, C., Srivastava, G., Dubey, A., Roy,. M., Jain, S., Sethy, N., et al. (2016). Nano-ironpyrite seed dressing: A sustainable intervention to reduce fertilizer consumption in vegetable (beetroot, carrot), spice (fenugreek), fodder (alfalfa), and oilseed (mustard, sesamum) crops. Nanotechnol. Environ. Eng. 1, 1-12. doi: 10.1007/s41204-016-0002-7

Davison, W. (1991). The solubility of iron sulphides in synthetic and natural waters at ambient temperature. Aquatic Sci. 53, 309-329. doi: 10.1007/BF00877139

\section{AUTHOR CONTRIBUTIONS}

All authors listed have made a substantial, direct and intellectual contribution to the work, and approved it for publication.

\section{ACKNOWLEDGMENTS}

This work was supported by the National Key R\&D Program of China (Grant No. 2018YFC1003500), as well as the National Natural Science Foundation of China (Grant Nos. 81930050, 81671810, and 31701236).

De Leeuw, N., Parker, S., Sithole, H., and Ngoepe, P. E. (2000). Modeling the surface structure and reactivity of pyrite: introducing a potential model for $\mathrm{FeS}_{2}$. J. Phys. Chem. B 104, 7969-7976. doi: 10.1021/jp0009498

Ding, B., Yu, C., Li, C., Deng, X., Ding, J., Cheng, Z., et al. (2017). Cis-platinum pro-drug-attached $\mathrm{CuFeS}_{2}$ nanoplates for in vivo photothermal/photoacoustic imaging and chemotherapy/photothermal therapy of cancer. Nanoscale 9, 16937-16949. doi: 10.1039/C7NR04166G

Ding, C., Yan, Y., Xiang, D., Zhang, C., and Xian, Y. (2016). Magnetic $\mathrm{Fe}_{3} \mathrm{~S}_{4}$ nanoparticles with peroxidase-like activity, and their use in a photometric enzymatic glucose assay. Microchim. Acta 183, 625-631. doi: 10.1007/s00604-015-1690-6

Dong, H., Fan, Y., Zhang, W., Gu, N., and Zhang, Y. (2019). Catalytic mechanisms of nanozymes and their applications in biomedicine. Bioconjug. Chem. 30, 1273-1296. doi: 10.1021/acs.bioconjchem.9b00171

Elliot, A. (2010). Structure of pyrrhotite $5 c\left(\mathrm{Fe}_{9} \mathrm{~S}_{10}\right)$. Acta Crystallogr. Section B 66, 271-279. doi: 10.1107/S0108768110011845

Esmaeili, E., Eslami-Arshaghi, T., Hosseinzadeh, S., Elahirad, E., Jamalpoor, Z., Hatamie, S., et al. (2020). The biomedical potential of cellulose acetate/polyurethane nanofibrous mats containing reduced graphene oxide/silver nanocomposites and curcumin: antimicrobial performance and cutaneous wound healing. Int. J. Biol. Macromol. 152, 418-427. doi: 10.1016/j.ijbiomac.2020.02.295

Feng, M., Lu, Y., Yang, Y., Zhang, M., Xu, Y., Gao, H., et al. (2013). Bioinspired greigite magnetic nanocrystals: chemical synthesis and biomedicine applications. Sci. Rep. 3:994. doi: 10.1038/srep02994

Fleet, M. (1971). The crystal structure of a pyrrhotite $\left(\mathrm{Fe}_{7} \mathrm{~S}_{8}\right)$. Acta Cryst. B 27:1864 doi: $10.1107 /$ S0567740871004990

Fu, D., Liu, J., Ren, Q., Ding, J., Ding, H., Chen, X., et al. (2019). magnetic iron sulfide nanoparticles as thrombolytic agents for magnetocaloric therapy and photothermal therapy of thrombosis. Front. Mater. 6:316. doi: 10.3389/fmats.2019.00316

Gan, Y., Xu, F., Luo, J., Yuan, H., Jin, C., Zhang, L., et al. (2016). One-pot biotemplate synthesis of $\mathrm{FeS}_{2}$ decorated sulfur-doped carbon fiber as high capacity anode for lithium-ion batteries. Electrochim. Acta 209, 201-209. doi: 10.1016/j.electacta.2016.05.076

Ganbaatar, N., Matsuzaki, N., Nakazawa, Y., Afrin, R., Aono, M., Yano, T., et al. (2016). Surface force analysis of pyrite $\left(\mathrm{FeS}_{2}\right)$ : its reactivity to amino acid adsorption. Adv. Mater. Phys. Chem. 6, 167-176. doi: 10.4236/ampc.2016.67018

Gao, L., Zhuang, J., Nie, L., Zhang, J., Zhang, Y., Gu, N., et al. (2007). Intrinsic peroxidase-like activity of ferromagnetic nanoparticles. Intrinsic peroxidaselike activity of ferromagnetic nanoparticles. Nat. Nanotechnol. 2, 577-583. doi: 10.1038/nnano.2007.260

Gao, S., Huang, F., Song, D., Li, G., Liu, Q., Feng, T., et al. (2015). "Growth mechanism and stability study on the $\mathrm{Fe}_{3} \mathrm{~S}_{4}$ nanocrystals synthesized under thermal and humid conditions," in Proceedings of the 11th International Congress for Applied Mineralogy. doi: 10.1007/978-3-319-13948-7_13

Guan, G., Wang, X., Li, B., Zhang, W., Cui, Z., Lu, X., et al. (2018). “Transformed” $\mathrm{Fe}_{3} \mathrm{~S}_{4}$ tetragonal nanosheets: a high-efficiency and body-clearable agent for magnetic resonance imaging guided photothermal and chemodynamic synergistic therapy. Nanoscale 10, 17902-17911. doi: 10.1039/C8NR 06507A 
Guo, S., Li, J., Ma, Z., Chi, Y., and Xue, H. (2016). A facile method to prepare $\mathrm{FeS} /$ porous carbon composite as advanced anode material for lithium-ion batteries. J. Mater. Sci. 52, 2345-2355. doi: 10.1007/s10853-016-0527-y

Guo, Z., Sun, F., Han, B., Lin, K., Zhou, L., and Yuan, W. (2017). Iron vacancy in tetragonal $\mathrm{Fe}_{1-\mathrm{X}} \mathrm{S}$ crystals and its effect on the structure and superconductivity. Phys. Chem. Chem. Phys. 19, 9000-9006. doi: 10.1039/C7CP $00068 \mathrm{E}$

He, Q., Huang, C., and Liu, J. (2013). Preparation, Characterization and antibacterial activity of magnetic greigite and $\mathrm{Fe}_{3} \mathrm{~S}_{4} / \mathrm{Ag}$ nanoparticles. Nanosci. Nanotechnol. Lett. 5, 1-8. doi: 10.1166/nnl.2014.1727

He, Y., Wilson, J., Su, C., and Wilkin, R. T. (2015). Review of abiotic degradation of chlorinated solvents by reactive iron minerals in aquifers. Ground Water Monitoring Remediation 35, 57-75. doi: 10.1111/gwmr.12111

Jin, A., Mi-Ju, K., Kug-Seung, L., Yu, S., and Sung, Y. (2019). Spindle-like $\mathrm{Fe}_{7} \mathrm{~S}_{8} / \mathrm{N}-$ doped carbon nanohybrids for high-performance sodium ion battery anodes. Nano Res. 12, 695-700. doi: 10.1007/s12274-019-2278-y

Jin, J., Wu, W., Min, H., Wu, H., Wang, S., Ding, Y., et al. (2017). A glassy carbon electrode modified with $\mathrm{FeS}$ nanosheets as a highly sensitive amperometric sensor for hydrogen peroxide. Microchim. Acta 184, 1389-1396. doi: 10.1007/s00604-017-2105-7

Jin, Q., Liu, J., Zhu, W., Dong, Z., Liu, Z., and Cheng, L. (2018). Albumin-assisted synthesis of ultrasmall $\mathrm{FeS}_{2}$ nanodots for imaging-guided photothermal enhanced photodynamic therapy. ACS Appl. Mater. Interfaces 10, 332-340. doi: $10.1021 /$ acsami.7b16890

Kar, S., and Chaudhuri, S. (2004). Solvothermal synthesis of nanocrystalline $\mathrm{FeS}_{2}$ with different morphologies. Chem. Phys. Lett. 398, 22-26. doi: 10.1016/j.cplett.2004.09.028

Kasting, J. (1993). Earth's early atmosphere. Science 259, 920-926. doi: $10.1126 /$ science. 11536547

Kavner, A., Duffy, T., and Shen, G. (2001). Phase stability and density of FeS at high pressures and temperatures: implications for the interior structure of Mars. Earth Planet. Sci. Lett. 185, 25-33. doi: 10.1016/S0012-821X(00)00356-3

Kim, E. J., and Batchelor, B. (2009). Synthesis and characterization of pyrite (FeS2) using microwave irradiation. Mater. Res. Bull. 44, 1553-1558. doi: 10.1016/j.materresbull.2009.02.006

Kong, X., Lou, T., and Li, Y. (2005). $\mathrm{Fe}_{7} \mathrm{~S}_{8}$ nanorods and nanosheets. J. Alloys Compd. 390, 236-239. doi: 10.1016/j.jallcom.2004.07.054

Kuhn, S. J., Eskildsen, M. R., Debeer-Schmitt, L., Li, L., de La Cruz, C., and Sefat, A. S. (2016). Structure and magnetic interactions in FeS: a low-Tc superconductor. Bull. Am. Phys. Soc. 61, 2. Abstracts retrieved from APS March Meeting (Abstract ID: BAPS.2016.MAR.H11.12).

Kwon, K., Refson, K., Bone, S., Qiao, R., Yang, W., Liu, Z., et al. (2011). Magnetic ordering in tetragonal FeS: evidence for strong itinerant spin fluctuations. Phys. Rev. B Cond. Matt. 83, 064402.1-064402.7. doi: 10.1103/PhysRevB.83.064402

Lefèvre, C., Abreu, F., Lins, U., and Bazylinski, D. (2010). Nonmagnetotactic multicellular prokaryotes from low-saline, nonmarine aquatic environments and their unusual negative phototactic behavior. Appl. Environ. Microbiol. 76, 3220-3227. doi: 10.1128/AEM.00408-10

Li, M., Yao, Q., Zhou, G., Qu, X., Mu, C., and Fu, S. (2011). Microwaveassisted controlled synthesis of monodisperse pyrite microspherolites. Cryst. Eng. Comm. 13, 5936-5942. doi: 10.1039/c1ce05478c

Li, X., Xu, H., Chen, Z., Chen, Z., and Chen, G. (2011). Biosynthesis of nanoparticles by microorganisms and their applications. J. Nanomater. 2011, 1-16. doi: 10.1155/2011/270974

Li, Y., Pu, Q., Li, S., Zhang, H., Wang, X., Yao, H., et al. (2019). Machine learning methods for research highlight prediction in biomedical effects of nanomaterial application. Patt. Recognit. Lett. 117, 111-118. doi: 10.1016/j.patrec.2018.11.008

Liang, M., and Yan, X. (2019). Nanozymes: from new concepts, mechanisms, and standards to applications. Acc. Chem. Res. 52, 2190-2200. doi: 10.1021 acs.accounts.9b00140

Ma, J., Chang, L., Lian, J., Huang, Z., Duan, X., Liu, X., et al. (2010). Ionic liquidmodulated synthesis of ferrimagnetic $\mathrm{Fe}_{3} \mathrm{~S}_{4}$ hierarchical superstructures. Chem. Commun. 46, 5006-5008. doi: 10.1039/c0cc00479k

Manafi, A., Hosseini, M., Fakhri, A., Gupta, V., and Agarwal, S. (2019). Investigation of photocatalytic process for iron disulfide-bismuth oxide nanocomposites by using response surface methodology: structural and antibacterial properties. J. Mol. Liq. 289:110950. doi: 10.1016/j.molliq.2019.110950
Mann, S., Sparks, N., Frankel, R., Bazylinski, D., and Jannasch, H. (1990). Biomineralization of ferrimagnetic greigite $\left(\mathrm{Fe}_{3} \mathrm{~S}_{4}\right)$ and iron pyrite $\left(\mathrm{FeS}_{2}\right)$ in a magnetotactic bacterium. Nature $343,258-261$. doi: 10.1038/343258a0

Mei, B., and Ma, Z. (2013). Study of anti-friction performance of spherical FeS nanoparticle. Appl. Mechan. Mater. 475-476, 1334-1339. doi: 10.4028/www.scientific.net/AMM.475-476.1334

Menyeh, A., and O'Reilly, W. (1997). Magnetic hysteresis properties of fine particles of monoclinic pyrrhotite $\mathrm{Fe}_{7} \mathrm{~S}_{8}$. J. Geomag. Geoelectr. 49, 965-976. doi: $10.5636 /$ jgg. 49.965

Mofokeng, T., Mabena, G., Moloto, M. J., Shumbula, P. M., Mubiayi, P., and Nyamukamba, P. (2017). Temperature influence on the lactose capped metal sulphide nanoparticles. Chalcogenide Lett. 14, 347-355.

Mohindar, S., and Jagadeesh, M. (1979). Temperature-dependent magnetic susceptibility of marcasite (FeS_ $\{2\}$ ). Phys. Rev. B 20:3897. doi: 10.1103/PhysRevB.20.3897

Moore, J., Nienhuis, E., Ahmadzadeh, M., and Mccloy, J. (2019). Synthesis of greigite $\left(\mathrm{Fe}_{3} \mathrm{~S}_{4}\right)$ particles via a hydrothermal method. AIP Adv. 9:035012. doi: $10.1063 / 1.5079759$

Niño, M., Flores, E., Sanchez, C., and Rojo, J. (2018). Reactivity of a FeS surface under room temperature exposure to nitrogen and $\mathrm{H}_{2} \mathrm{~S}$. J. Phys. Chem. B 122, 705-712. doi: $10.1021 /$ acs.jpcb.7b06309

Ono, S. (2007). Magnetic phase transition of FeS at high pressures. Acta Crystallogr. Sect. A Found. Crystallogr. 63:59. doi: 10.1107/S0108767307098716

Paolella, A., George, C., Povia, M., Zhang, Y., Krahne, R., Gich, M., et al. (2011). Charge transport and electrochemical properties of colloidal greigite $\left(\mathrm{Fe}_{3} \mathrm{~S}_{4}\right)$ nanoplatelets. Chem. Mater. 23, 3762-3768. doi: 10.1021/cm201531h

Powell, A. V., Vaqueiro, P., Knight, K. S., Chapon, L. C., and Sánchez, R. D. (2004). Structure and magnetism in synthetic pyrrhotite $\mathrm{Fe}_{7} \mathrm{~S}_{8}$ : a powder neutrondiffraction study. Phys. Rev. B 70, 014415. doi: 10.1103/PhysRevB.70.014415

Qi, W., and Cowan, J. (2011). Structural, mechanistic and coordination chemistry of relevance to the biosynthesis of iron-sulfur and related iron cofactors. Coord. Chem. Rev. 255, 688-699. doi: 10.1016/j.ccr.2010.10.016

Rawat, M., Nayan, R., Negi, B., Zaidi, M. G. H., and Arora, S. (2017). Physio-biochemical basis of iron-sulfide nanoparticle induced growth and seed yield enhancement in b. juncea. Plant Physiol. Biochem. 118, 274-284. doi: 10.1016/j.plaphy.2017.06.021

Rickard, D. (2006). The solubility of FeS. Geochim. Cosmochim. Acta 70, 5779-5789. doi: 10.1016/j.gca.2006.02.029

Rickard, D., and Luther, G. (2007). Chemistry of iron sulfides. Chem. Rev. 107, 514-562. doi: $10.1021 / \mathrm{cr} 0503658$

Roberts, A. (1995). Magnetic properties of sedimentary greigite $\left(\mathrm{Fe}_{3} \mathrm{~S}_{4}\right)$. Earth Planetary Sci. Lett. 134, 227-236. doi: 10.1016/0012-821X(95)00131-U

SantosCarballal, D., Roldan, A., Dzade, N., and de Leeuw, N. H. (2017). Reactivity of $\mathrm{CO}_{2}$ on the surfaces of magnetite $\left(\mathrm{Fe}_{3} \mathrm{O}_{4}\right)$, greigite $\left(\mathrm{Fe}_{3} \mathrm{~S}_{4}\right)$ and mackinawite (FeS). Philos. Trans. R. Soc. A 376:65. doi: 10.1098/rsta.2017.0065

Scaini, M., Bancroft, G., and Knipe, S. (1998). Reactions of aqueous $\mathrm{Au}^{1+}$ sulfide species with pyrite as a function of $\mathrm{pH}$ and temperature. Am. Mineral. 83, 316-322. doi: 10.2138/am-1998-3-415

Schoonen, M., Cohn, C., Roemer, E., Laffers, R., Simon, S., and O'Riordan, T. (2006). Mineral-induced formation of reactive oxygen species. Med. Mineraol. Geochem. 64, 179-221. doi: 10.2138/rmg.2006.64.7

Simeonidis, K., Liébana-Viñas, S., Wiedwald, U., Ma, Z., Li, Z.-A., Spasova, M., et al. (2016). A versatile large-scale and green process for synthesizing magnetic nanoparticles with tunable magnetic hyperthermia features. RSC Adv. 6, 53107-53117. doi: 10.1039/C6RA09362K

Snowball, I. (1991). Magnetic hysteresis properties of greigite $\left(\mathrm{Fe}_{3} \mathrm{~S}_{4}\right)$ and a new occurrence in holocene sediments from swedish lappland. Phys. Earth Planetary Interiors 68, 32-40. doi: 10.1016/0031-9201(91)90004-2

Srivastava, G., Das, A., Kusurkar, T., Roy, M., Airan, S., Sharma, R., et al. (2014a). Ironpyrite, a potential photovoltaic material, increases plant biomass upon seed pretreatment. Mater. Express 4, 23-31. doi: 10.1166/mex.2014.1139

Srivastava, G., Das, C. K., Das, A., Singh, S., Roy, M., Kim, H., et al. (2014b). Seed treatment with iron pyrite $\left(\mathrm{FeS}_{2}\right)$ nanoparticles increases the production of spinach. RSC Adv. 4, 58495-58504. doi: 10.1039/C4RA06861K

Usher, C., Paul, K., Narayansamy, J., Kubicki, J., Sparks, D., Schoonen, M., et al. (2005). Mechanistic aspects of pyrite oxidation in an oxidizing gaseous environment: an in situ HATR-IR isotope study. Environ. Sci. Technol. 39, 7576-7584. doi: 10.1021/es0506657 
Vanitha, P., and O’Brien, P. (2008). Phase Control In The Synthesis Of Magnetic iron sulfide nanocrystals from a cubane-type Fe-S cluster. J. Am. Chem. Soc. 130, 17256-17257. doi: 10.1021/ja8078187

Wadia, C., Wu, Y., Gul, S., Volkman, S., Guo, J., and Paul Alivisatos, A. (2009). Surfactant-assisted hydrothermal synthesis of single phase pyrite $\mathrm{FeS}_{2}$ nanocrystals. Chem. Mater. 21, 2568-2570. doi: 10.1021/cm901273v

Wang, X., Zhou, W., Zhou, Z., An, Y., and Wu, S. (2013). Shapecontrolled synthesis of iron sulfide nanostructures by thermal decomposition of organometallic precursors. Mater. Sci. Semicond. Proc. 16, 530-536. doi: 10.1016/j.mssp.2012.10.002

Wang, Z., Hu, T., Liang, R., and Wei, M. (2020). Application of zero-dimensional nanomaterials in biosensing. Front. Chem. 8:320. doi: $10.3389 /$ fchem. 2020.00320

Watson, J., Cressey, B., Roberts, A., Ellwood, D. C., Charnock, J., and Soper, A. K. (2000). Structural and magnetic studies on heavy-metal-adsorbing iron sulphide nanoparticles produced by sulphate-reducing bacteria. J. Magn. Magn. Mater. 214, 13-30. doi: 10.1016/S0304-8853(00)00025-1

Watson, J., Ellwood, D., Deng, Q., Mikhalovsky, S., Hayter, C. E., and Evans, J. (1995). Heavy metal adsorption on bacterially produced FeS. Minerals Eng. 8, 1097-1108. doi: 10.1016/0892-6875(95)00075-2

Watson, J., Ellwood, D., Soper, A., and Charnock, J. (1999). Nanosized stronglymagnetic bacterially-produced iron sulfide materials. J. Magnetism Magnetic Mater. 203, 69-72. doi: 10.1016/S0304-8853(99)00191-2

Wei, H., and Wang, E. (2013). Nanomaterials with enzyme-like characteristics (nanozymes): next-generation artificial enzymes. Chem. Soc. Rev. 42, 6060-6093. doi: 10.1039/c3cs35486e

Xiao, S., Cheng, M., Zhong, H., Liu, Z., Liu, Y., Yang, X., et al. (2020). Iron-mediated activation of persulfate and peroxymonosulfate in both homogeneous and heterogeneous ways: a review. Chem. Eng. J. 384:123265. doi: 10.1016/j.cej.2019.123265

Xie, J., Zhang, X., Wang, H., Zheng, H., Huang, Y., and Xie, J. (2012). Analytical and environmental applications of nanoparticles as enzyme mimetics. Trac Trends Analyt. Chemistry 39, 114-129. doi: 10.1016/j.trac.2012.03.021

Xu, Z., Qiu, Z., Liu, Q., Huang, Y., Li, D., Shen, X., et al. (2018). Converting organosulfur compounds to inorganic polysulfides against resistant bacterial infections. Nat. Commun. 9:3713. doi: 10.1038/s41467-018-06164-7
Yang, K., Yang, G., Chen, L., Cheng, L., Wang, L., Ge, C., et al. (2015) FeS nanoplates as a multifunctional nano-theranostic for magnetic resonance imaging guided photothermal therapy. Biomaterials 38, 1-9. doi: 10.1016/j.biomaterials.2014.10.052

Yang, W., Xiang, C., Xu, Y., Chen, S., Zeng, W., Liu, K., et al. (2020). Albumin-constrained large-scale synthesis of renal clearable ferrous sulfide quantum dots for T1-Weighted MR imaging and phototheranostics of tumors. Biomaterials 255:120186. doi: 10.1016/j.biomaterials.2020. 120186

Yao, W., Zhu, H., Li, W., Yao, H., Wu, Y., and Yu, S. (2013). Intrinsic peroxidase catalytic activity of $\mathrm{Fe}_{7} \mathrm{~S}_{8}$ nanowires templated from $\left[\mathrm{Fe}_{16} \mathrm{~S}_{20}\right] /$ diethylenetriamine hybrid nanowires. Chem. Plus Chem. 78, 723-727. doi: 10.1002/cplu.201300075

Yosida, K. (1951). Note on the magnetic properties of the $\mathrm{FeS}_{\mathrm{n}}$ system. Progr. Theor. Phys. 6, 356-365. doi: 10.1143/ptp/6.3.356

Zhang, L., and Webster, T. (2009). Nanotechnology and nanomaterials: promises for improved tissue regeneration. Nano Today 4, 66-80. doi: 10.1016/j.nantod.2008.10.014

Zhang, M., Cui, Z., and Jiang, H. (2018). Relative stability of $\mathrm{FeS}_{2}$ polymorphs with the random phase approximation approach. J. Mater. Chem. A 6:6606. doi: 10.1039/C8TA00759D

Zhao, Q., Yi, X., Li, M., Zhong, X., Shi, Q., and Yang, K. (2016). High near-infrared absorbing $\mathrm{Cu}_{5} \mathrm{FeS}_{4}$ nanoparticles for dual-modal imaging and photothermal therapy. Nanoscale 8, 13368-13376. doi: 10.1039/C6NR0 $4444 \mathrm{~A}$

Conflict of Interest: The authors declare that the research was conducted in the absence of any commercial or financial relationships that could be construed as a potential conflict of interest.

Copyright (c) 2020 Yuan, Wang and Gao. This is an open-access article distributed under the terms of the Creative Commons Attribution License (CC BY). The use, distribution or reproduction in other forums is permitted, provided the original author(s) and the copyright owner(s) are credited and that the original publication in this journal is cited, in accordance with accepted academic practice. No use, distribution or reproduction is permitted which does not comply with these terms. 